\title{
THE CULTURE OF FRUIT TREES IN POTS
}

$\Delta x$

JOSH BRACE 


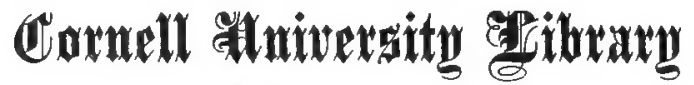

BOUGHT WITH THE INCOME FROM THE

SAGE ENDOWMENT FUND THE GIFT OF

\section{Meury W. Sage}

$$
\text { r89x }
$$

A.201734

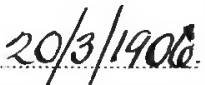

\section{RETURN TO}

\section{ALBERT R. MANN LIBRARY}

ITHACA, N. Y. 


\section{SB 356.B79}

Cornell University Library

The culture of fruit trees in pots,

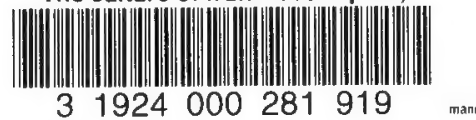




\section{Cornell University Library}

The original of this book is in the Cornell University Library.

There are no known copyright restrictions in the United States on the use of the text.

http://www.archive.org/details/cu31924000281919 
THE CULTURE OF FRUIT TREES

IN POTS 




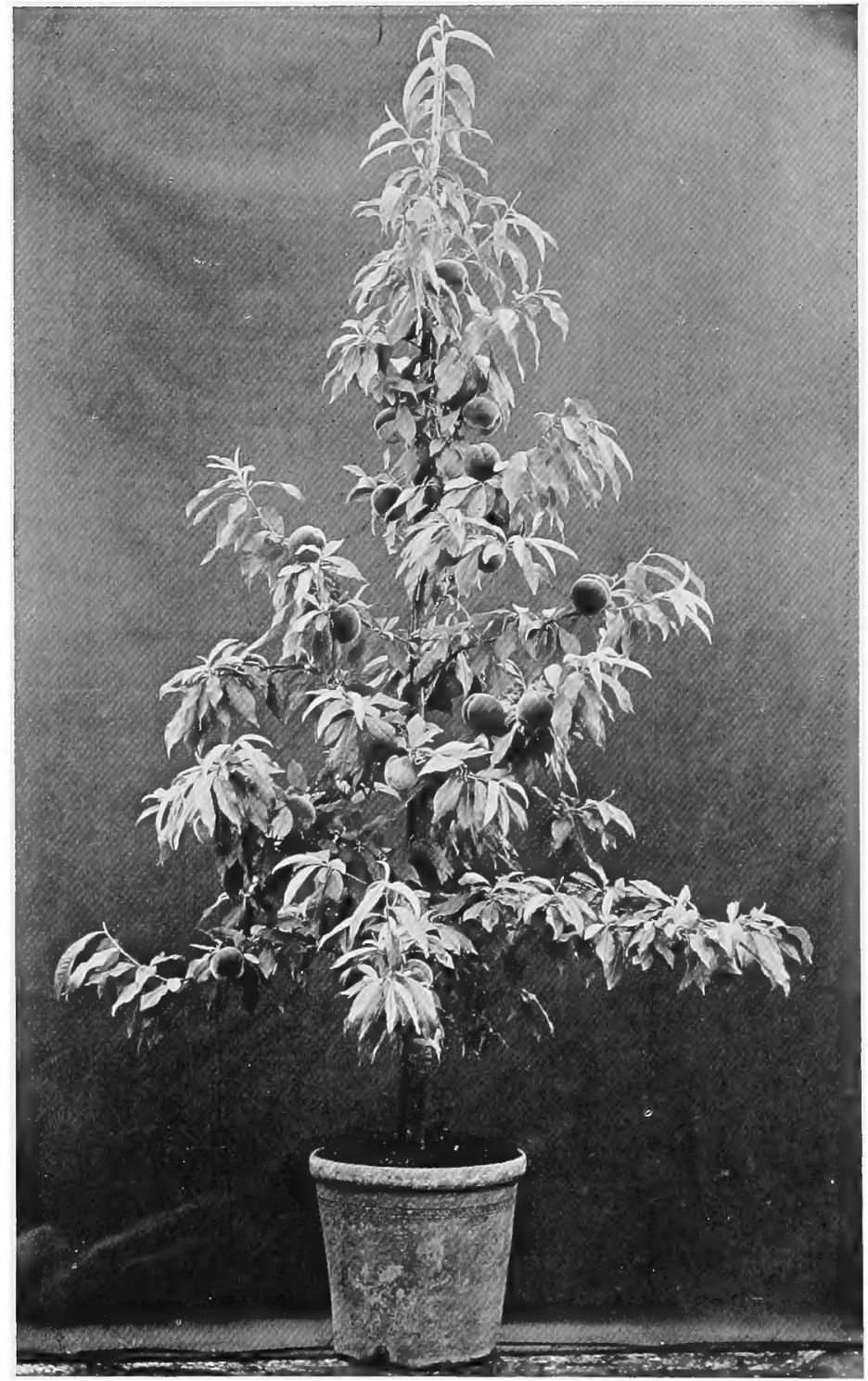

PYRAMID OF PEREGRINE PEACH. 




\section{THE CULTURE OF}

\section{FRUIT TREES IN POTS}

BY JOSH BRACE

LONDON

JOHN MURRAY, ALBEMARLE STREET

I 904 
PRINTED BY

WILLIAM CLOWES AND SONS, LIMITED, LONDON AND BECCLES. 


\section{PREFACE}

Mr chief aim in writing this book is to lay down those rules of management of fruit trees in pots which, from a lifelong experience, I have found to be essential to success. I hare aroided theory as far as possible, and confined myself to the advocacy of what is simple, practical, and useful, and I have endeavoured to treat each step in the process with the utmost clearness and care, so as to avoid as far as possible any chance of mistake on the part of those who wish to adopt my method.

The severe frosts that occurred between the years 1850 and 1860, and especially those of the year 1860, destroyed all the fruit out-of-doors. It then occurred to the late Mr. 'T. Rivers that something should be done to protect fruit trees from frosts, especially during the flowering stage. The result was the construction of the "orchard house," or glass structure without artificial heat. 
These houses have been found invaluable ever since.

In 1903 nearly all the fruit out-of-doors was destroyed by the severe spring frosts, while fruit trees in the orchard houses yielded magnificent and abundant crops. I venture to say, without fear of contradiction, that orchard houses are the most trustworthy structures to insure a good crop of fruit every year. The protection afforded by glass was at first thought sufficient to keep out all frost, but as time went on, it was deemed advisable to make assurance doubly sure by using a little artificial heat in the event of a severe frost.

'The disappointment to fruit-growers due to the uncertainty of our climate, combined with the satisfactory results achieved by the orchardhouse system, tend towards a wide adoption of this already popular method of cultivation, and those who avail themselves of it will, I feel sure, have little cause to regret the initial outlay.

For three generations the cultivation of fruit trees in pots has been one of the leading features of the firm of Thomas Rivers \& Son. In their nursery at Sawbridgeworth I have been employed as orchard-house foreman for the last twenty-two years, so I may fairly claim to have 


\section{PREFACE}

derived abundant practical experience from the best source.

In the preparation of this book I have met with many difficulties: some have appeared almost insurmountable, but with the help of kind friends these difficulties have disappeared. I take this opportunity to return them my heartfelt thanks, and to God be all the praise.

J. B.

SAWBRIDGEWORTH,

September, 1904. 



\title{
CONTENTS
}

\author{
CHAPTER I \\ INTRODUCTORY
}

Houses and their construction-Selection of the site-PotsPAGE

Soil-Stocks-Span-roofed houses-Three-quarter spanLean-to houses-Ventilation-Inexpensive houses-Wire houses-Protection against birds-Water--Cost of con$\begin{array}{lllllll}\text { struction } & \ldots & \ldots & \ldots & \ldots & \ldots & \ldots\end{array}$

\section{CHAPTER II}

\section{THE FURNISHING OF THE HOUSE}

Number of trees required-Arrangement of the trees-Beds and borders-The need for separate compartments

\section{CHAPTER III}

\section{CUITURAL DETAILS}

The forms of trees-Potting-Soil-Potting-hook and prongPerforated pots-Method of forcing-Pruning-Pinching -Hide-bound trees-Surface dressing-Number of fruits on a tree-Cost of trees-Longevity, etc. $\quad \ldots \quad \quad \ldots$

\section{CHAPTER IV}

\section{VARIETIES OF FRUITS}

Peaches and nectarines-Apricots-Plums-Cherries-Apples and pears-Baking pears-The mulberry-The fig-The vine 


\section{CHAPTER V \\ INSECT AND OTHER PESTS}

Green fly-Brown aphis-Red spider-Thrip-Earwigs-

$\begin{array}{llllll}\text { Weevils-Ants-Mildew, etc. } & \ldots & \ldots & \ldots & 79\end{array}$

\section{CHAPTER VI}

a Calendar of operations iN the UNHEATED HOUSE FOR EACH MONTH OF THE YEAR

\section{CHAPTER VII}

\section{MISCELLANEOUS OBSERVATIONS}

Flavour-Gathering the fruit-Fruit trees for decorative purposes-Miscellaneous directions, etc.

EXPLANATORY NOTES TO PLANS $\quad \ldots \quad \ldots \quad \ldots 107$ 


\section{LIST OF ILLUSTRATIONS}

The illustratious of Fruit Trees in l'ots are from photographs of trees grown in the Sawbridgeworth Nurseries. For the use of the trees for photographing, the Author begs to return his best thanks to Messrs. Thomas Rivers \& Son.

PYRAMID OF I'EREGRINE PEACH

TO FACE PAGE Frontisyiece

PYRAMID OF PITMASTON DUCHESS PEAR $\quad \ldots \quad 16$

HALF STANDARD OF EMPEROR FRANCIS CHERRY 32

BUSH OF LORD NAPIER NECTARINE $\quad \ldots \quad$... 40

PYRAMID OF EARLY RIVERS NECTARINE $\quad \ldots \quad 48$

$\begin{array}{llllll}\text { HALF STANDARD OF } & \text { EARLY } & \text { RIVERS PEACH } & \ldots & 64\end{array}$

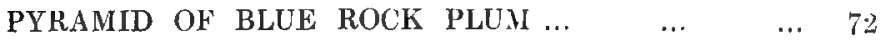

$\begin{array}{llllllll}\text { HALF STANDARD OF } & \text { PEACH } & \text { APRICOT } & \ldots & \ldots & 80\end{array}$

PYRAMID OF KING OF TOMPKINS COUNTY APPLE 92 



\section{THE CULTURE OF FRUIT TREES IN POTS}

\section{CHAP'TER I}

\section{INTRODUCTORY}

Houses and their construction-Selection of the site--Pots-SoilStocks - Span-roofed houses - Three-quarter spau - Lean-to houses-Ventilation-Inexpensive houses-Wire houses-Protection against birds-Water-Cost of construction.

Houses and their construction. - Various kinds of fruit trees have now for many years been grown in pots. Their culture has been a source of great pleasure, and with some the results have been all that could be desired. But many have been unfortunate, and their labours have ended in failure and disappointment. This has caused pot culture to be condemned-simply because the secret of failure on the one hand, and the conditions of success on the other, have never been known. Many people have grown their pot-trees in houses absolutely unfit for their culture, e.g. in a vinery, where the heat has been far too great. 
the shade too dense, and the ventilation insufficient. Another house may have been situated near large trees, which have shut out all-or very much - of the sunlight, which is essential for the wellbeing of fruit trees. 'The consequence has been that all fruit produced has suffered in size, colour, and flarour. The wood of such trees, too, has never ripened, and so in the following year the immature buds have given no fruit; hence the failure.

Before proceeding further, the following simple directions may be laid down :-

First.-Choose a favourable site on which to build a suitable, properly constructed house.

Second.-Use pots of a proper size for the trees, avoiding those of too large a size, as this is one of the greatest mistakes, and one often fatal to the trees.

Third.-Use the right kind of soil, and purchase your trees from a reliable firm.

The selection of the right stocks for the different varieties of fruit trees is a matter for the nurseryman, and is a point to which Messrs. Rivers have always paid great attention.

The span-Roof house: ITS SITE.-'There are few people who would think of purchasing household furniture unless they had a house for its accommodation, and it would be equally ridiculous to purchase fruit trees in pots without a 
house in which to grow them. The first consideration, then, should be - the site for the house.

This should always be an open space, on level ground, away from the shade of any trees-or even high walls - so as to get the full benefit of all light, sun, and air.

The next thing to decide is the form of house. This should, wherever possible, most certainly be a span-roof, running north to south. The house should by no means be an elaborate structure, but a useful one. The employment of too much iron or stone should always be aroided, as both have a tendency to absorb much of the moisture which is so beneficial to the trees. Wood is far better than either of the above-mentioned materials. 'The space available for building will always decide the size of the house. The dimensions may range from $14,16,18,20,22$, to $24 \mathrm{ft}$. in width, and be of any length. Where a good substantial house is required the foundation should be of brickwork, viz. 9 -in. work in the ground (the extent of which must be decided by the solidity of the ground), and about two courses of 9 -in. work above ground, terminating with two courses of $4 \frac{1}{2}$-in. work, on which the wooden sill will rest. The plan is correctly drawn to scale, and the various details are fully explained in the notes. 
The front and side ventilators are 18 ins. wide, and are made with three 6 -in. $\times \frac{3}{4}$-in. match-boards, which undoubtedly are the best. These ventilators should always open downwards, as by so doing all cold currents of air are aroided.

'There should be a panel door at each end of the house, of the following dimensions : height, $7 \mathrm{ft}$. ; width, $3 \mathrm{ft}$; wood, $1 \frac{1}{2}$ in. in thickness.

There are three top rentilators on the south side and two on the north side. (See bird's-eye view of plan No. 5.)

I am a great advocate for top ventilation; and should prefer top ventilators, running alternately the whole length of the house.

The rafters of the house are 20 ins. apart, and the best-sized squares of glass are those 20 ins. $\times$ 15 ins. The best glass to use is the $21-\mathrm{oz}$, and the best kind of glazing is the single glazing, viz. a bed of putty at the bottom only, and no top putty, as each square of glass can be made secure by small brads being driven into the rafters.

The columns referred to in plan should each have a flange screwed on to the bottom about 6 ins. in diameter, and should be sunk into the ground about 9 or 12 ins.

It is a good plan to set them on two bricks, and then fill in with cement or concrete.

These columns will then have to be affixed to 


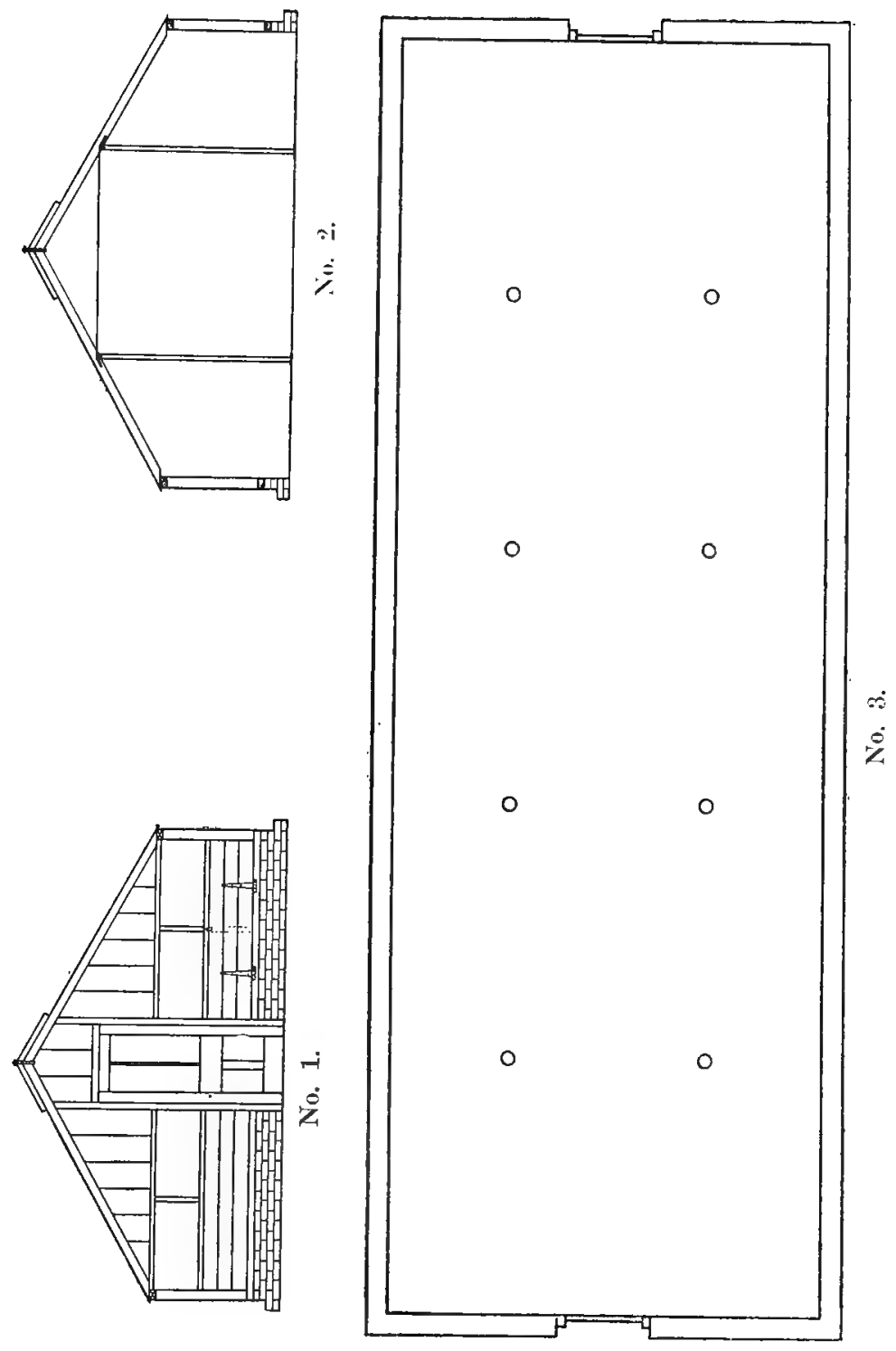


the $\mathbf{T}$ iron in the middle of the roof, and this can easily be done if a small scallop is made at the top sufficiently large to fit on to the $\mathbf{T}$ iron, and can be made secure by a rivet or screw.

All the posts will, of course, be mortised into both sill and plate, and will be inside the house, so that none are seen save the four corner posts. Any builder will easily understand this by referring to plan No. 4. All other details will be found in the same plan. With reference to rentilating gear, I should strongly advise the use of the lever in all cases, as it is far more substantial, and economizes labour.

It will be absolutely necessary to keep the birds out of the house, and this is best done by placing wire netting all round the ventilators inside. The best kind of netting is the $\frac{3}{4}$-in. mesh galvanized wire netting. 'This can be nailed on the posts inside the house, and will thus set all birds at defiance. With reference to brads mentioned for glazing purposes, an expert has informed me that the best kind of brads are the $\frac{3}{4}$-in. "shoe brads," as they have rery small heads, and are less liable to crack the glass. Having giren a somewhat lengthened description of the house $18 \mathrm{ft}$. wide, etc., I will now proceed to describe the large house referred to on p. 24.

'This house will, of course, be larger in every 

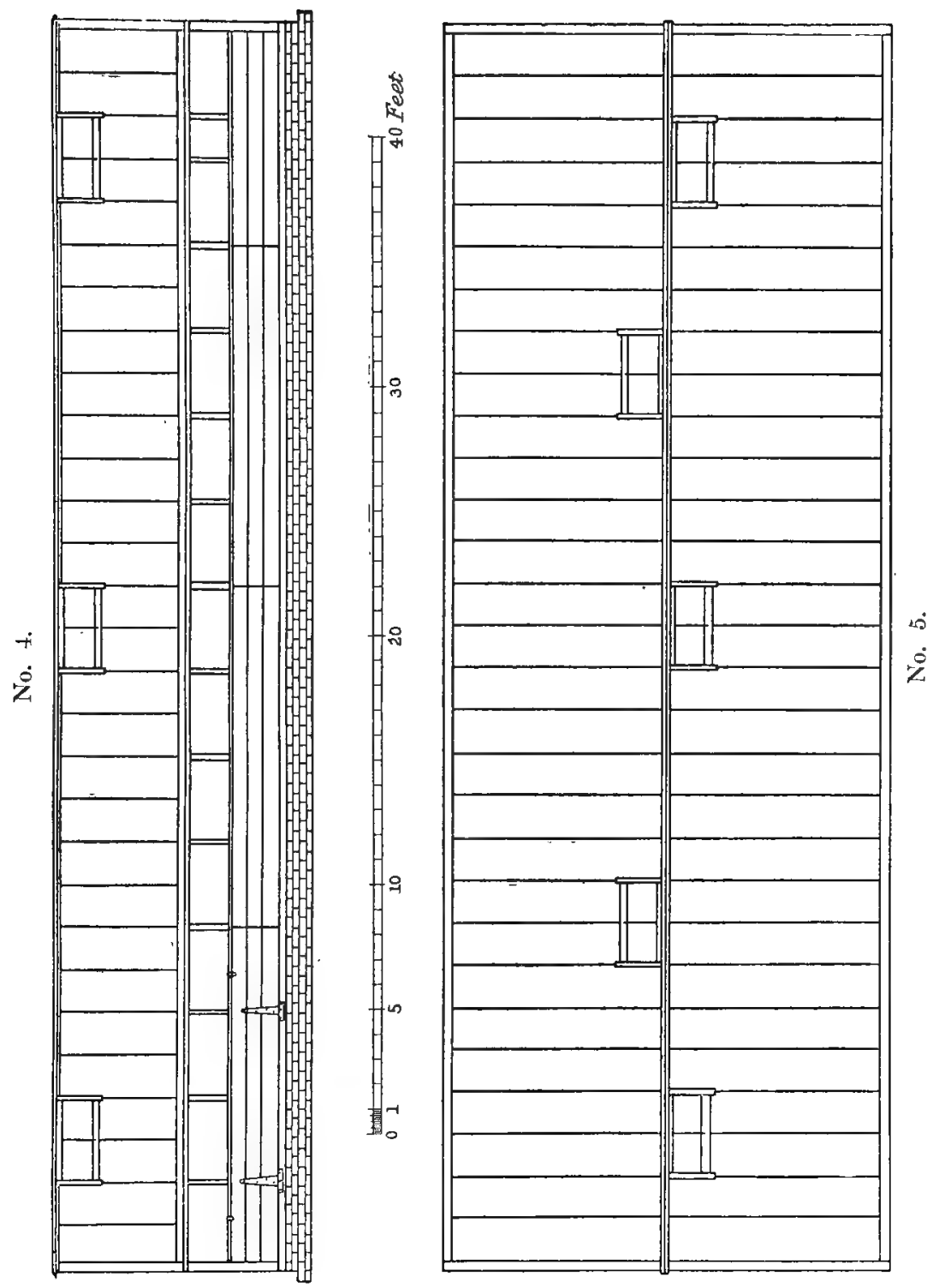
way, and will of necessity require more supports than the one previously described.

The dimensions of the house will be as follows : width, 24 ft. ; height at apex, $12 \mathrm{ft}$. ; height at eaves, $5 \mathrm{ft}$. 6 ins. ; length, from 50 to 100 or more $\mathrm{ft}$. ; but where space and means permit, I strongly recommend $100 \mathrm{ft}$.

For side supports of this house, I should advise the use of " oak posts" as principal posts, and these should be 5 or $6 \mathrm{ft}$. apart. They should be sunk in the ground to a sufficient depth to make them quite firm and safe for the rafters to rest upon. Some people adopt the plan of inserting posts in "iron sockets," others prefer to tar them, while some think it better to char them. The posts should be about 6 ins. wide and 4 ins. thick, and each interval, i.e. from post to post, should be bricked in ( $4 \frac{1}{2}$-in. work above ground) to a sufficient height to allow for sill, rentilators, and glass above, to the eare plate. (See plan of $18 \mathrm{ft}$. wide house.)

It will be noticed in the plan that there are two courses of 9 -in. work above ground, but in the large house this will not be necessary, as the oak posts will be sunk in the ground instead of resting on the sill, as in $18 \mathrm{ft}$. wide house.

The use of a sill will be of great advantage in the intervals between the oak posts, and if 
mortised into the posts, it will make an excellent support for the smaller posts in the intervals. These posts should be $3 \frac{1}{4}$ ins. $\times 2 \frac{1}{4}$ ins., and if mortised into the sill and eave plate, they will strengthen the side of house considerably.

The side ventilators should be the same as those in plan - the bar above, and glass to eaves also the same.

The rafters of the house may also be of the same depth-but no deeper-in fact, rather less, as a deep rafter is a mistake. Iron columns like those in the plan should be used, but not $\mathrm{T}$ irons, as this will not be strong enough. A substitute for $T$ irons would be a wooden purlin running the whole length of the house in the middle of the rafters. This should not exceed $4 \frac{1}{2}$ ins. in depth and 3 ins. in width.

These columns should be placed 8 or $10 \mathrm{ft}$. apart, but not more. Each column should have a flange at the top (similar to that at the bottom), and each column should be made secure by being screwed into the purlin. It is a good plan to have, in addition to the purlin, a bar of iron $\frac{3}{4}$ in. $\times \frac{1}{4}$ in. running the whole length of the house, and screwed on to each rafter to keep them in position.

There should be two of these bars of iron, one above and the other below the purlin, at equal distances from eaves and apex. The distance of 
the rafters, the size of glass and glazing, etc., the same as advised for the house $18 \mathrm{ft}$. wide.

The last, but by no means the least, point to decide is the top ventilation of the house. I strongly advocate plenty of top ventilation, and recommend a ventilator running the whole length of the house on both sides alternately, as used by our leading florists and market gardeners in their houses. There is a great advantage in having ventilators on both sides of a house, for in the event of cold or strong winds blowing from the north, the ventilators on the south side can be utilized, or vice versâ. There is also the means of introducing more air when required.

In this house $24 \mathrm{ft}$. wide, etc., there should be double instead of single doors at each end, and each door should be $2 \frac{1}{2} \mathrm{ft}$. wide, thus giving a space $5 \mathrm{ft}$. instead of 3 . The height of the doors should be the same as in the plan.

Cross-tie irons, of the same dimensions as those in the plan, should be used, as they will serve to keep the roof of house in position.

Where more than one "span-roof house" is required, each house should be an independent house, and not a succession of what is commonly known as the "ridge and gutter" houses, as these houses are not well adapted for growing "fruit trees" in pots. This matter should be strictly 
observed, for the adrantages of independent houses are many.

With different growers of fruit trees in pots there are different requirements; in some cases it will be necessary to advance, in other cases to retard, the ripening of the fruits grown by them. In an independent house this is easily accomplished, as the temperature can be increased or decreased at pleasure. Another great advantage is, that during the winter months the whole of the trees grown in two houses during the growing season may be placed in one house. The other house can then be used for another purpose until the growing season recommences, when the trees can again be transferred to their proper quarters.

THE "THREE-QUARTER SPAN" AND "ILEAN-TO Houses."-Although the "span-roofed house" is by far the best, and should always be used if possible, still, it may not be convenient for every one to build them, yet there may be a good wall to which a three-quarter span or lean-to house could be easily attached, and so converted into a very useful and profitable structure.

It need hardly be stated, with regard to houses of this class, that the details of construction should be identical with those of the span-roofed house.

It would be a grave error to have the house too low at the eares; but let there be a good pitch, 
say $5 \mathrm{ft}$. or $5 \mathrm{ft}$. 6 ins., according to the size of the house, as this will give good head space for the trees. 'The front and top ventilators should be of the same size as those of the span-roofed house, and in addition to these (if it be possible) there should be some ventilators in the back wall. These might take the form of flaps or slides, whichever is preferred, and should be about $3 \mathrm{ft}$. long and $1 \mathrm{ft}$. wide, and $6 \mathrm{ft}$. apart. These ventilators will be of great service, as they will be the outlets for any stagnant or hot air which is sure to be found in the back of "lean-to houses." Below is a rough diagram of the back of a lean-to house, showing how the ventilators may be arranged.

\section{Pools}

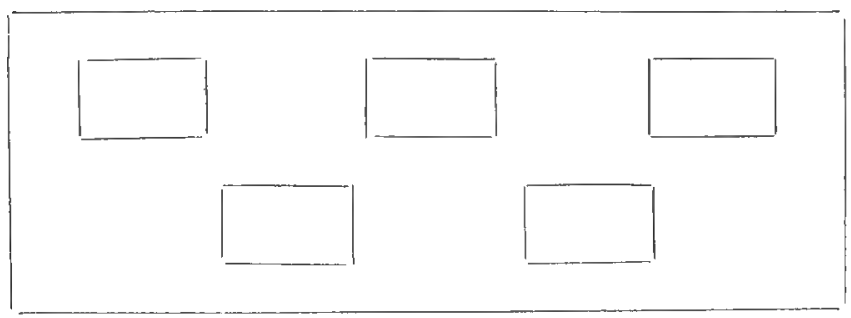

Frook

It will be noticed in the diagram that there are two rows of ventilators placed alternately, at equal distances, from both roof and floor of house. If the house is a small one, one row of rentilators 
only will be necessary. These should be in the centre of the wall. Of course, there are various ways of utilizing a lean-to house. Some people prefer a border at the back, whilst others object to this. 'The situation of door will be governed by it. 'The door should be of sufficient width to allow for the trees being taken in or out of the house as necessity may require. It is scarcely necessary to add, that both three-quarter span and lean-to houses should always face south.

USEFUI AND INEXPENSIVE HoUses.- Hitherto I have described houses of a substantial and wellbuilt character, and these I strongly advocate especially where artificial heat is to be used. Houses of another class, of much, or quite the same, shape and size, may be built with cheaper material. Such houses are capable of rendering rery good service, especially span-roofed houses. Oak posts should be used for the side supports of the house, and if a large house be required, these posts should be 6 ins. wide and 4 ins. thick. They may be sunk into the ground $2 \mathrm{ft}$. or $2 \mathrm{ft}$. 6 ins., and may be put either into iron sockets or charred and tarred, as before mentioned. These posts should be 5 or $6 \mathrm{ft}$. apart, and between each a few courses of $4 \frac{1}{2}$-in. brickwork should be used. It will only be necessary to have one or two courses above ground, as the remaining space to the rentilator 
will require no brickwork. As a substitute matchboarding should be used, and simply made secure by being nailed on to the oak posts.

This will greatly reduce the cost of building, as wood is far cheaper than bricks. The remain ing portion of the house should be, of course, exactly the same as previously mentioned. Leanto houses will require to hare oak posts both back and front, of the same size as before mentioned, and also at the same distances apart. 'The intervals from post to post will be filled up with a few courses of bricks and match-boarding, unless double boarding be preferred, i.e. where the back posts are correred in on both sides. Such being the case, I would recommend the use of featheredged boards outside and match-boards inside the house.

If single boards only are used on the back of the house, they should be nailed inside the house, as it will be better if the back is made use of, and will give a far neater appearance to the house.

In all cases side ventilators should open downwards, as previously stated. For houses not $14 \mathrm{ft}$. in width, the 12 -in. ventilators will be large enough. All houses above 14 ft. should have the 18-in. ventilators.

It should be clearly understood that, as a rule, all posts should be inside the house. The only 
exception being the back of the lean-to house composed of wood.

No mention has hitherto been made of the use of what is known as "principal rafters" in the building of houses, and the reason for this omission is, that there is no necessity for them. Where a good purlin is used, and supported by iron columns 8 or $\mathbf{1 0} \mathrm{ft}$. apart, no principal rafters are needed. After all, they only help to shut out the light. A builder, having a plan of house submitted to him, might say, "Oh, this class of" house will not be strong enough; it will soon collapse;" but I can truthfully say that the cultivator will be perfectly safe in having one erected according to plan. There need not be any fear as to its being a collapsible structure. 'There are many houses of this class which have done twenty, thirty, and even forty years' good service, and still promise to weather the storm for many years to come. I can substantiate these statements.

These remarks apply to the class of house as shown in the plan, and not to the less-expensive houses, although the last-named structures will last a great number of years.

Wire houses.-Another very useful structure is a house or enclosure, out-of-doors, for the purpose of growing hardy fruits, especially pears and apples, during the summer and autumn. It will 
also be found invaluable for protecting plums during the winter and early spring.

This structure can be either in the form of a square, a span, or a lean-to, with supports sufficiently strong to support galvanized wire-netting. This netting should be a $\frac{3}{4 i}$-in. mesh, as this will set the enemies of the above-mentioned fruits at defiance. The chief foes of the apple and pear are tomtits, whilst the worst enemy of plum trees is the bullfinch.

Nothing can be more annoying and discouraging than to find the choicest specimens of apples and pears punctured by tomtits. It is certain that the best specimens will suffer. Instinct seems to guide the birds in their selection of the best.

Plums will be sure to suffer more or less during the winter, especially in severe weather, from the attack of bullfinches, as these birds are very fond of the bloom-buds of plums, and if unchecked, they will deprive the tree of a very large percentage, and so cause a small crop.

Whatever form the wire house may take, it will be covered with wire-netting instead of glass. It will do excellent service if used as follows. When the pot-trees of pears and apples have passed through their period of protection in the glass house, they should be placed out-of-doors, 


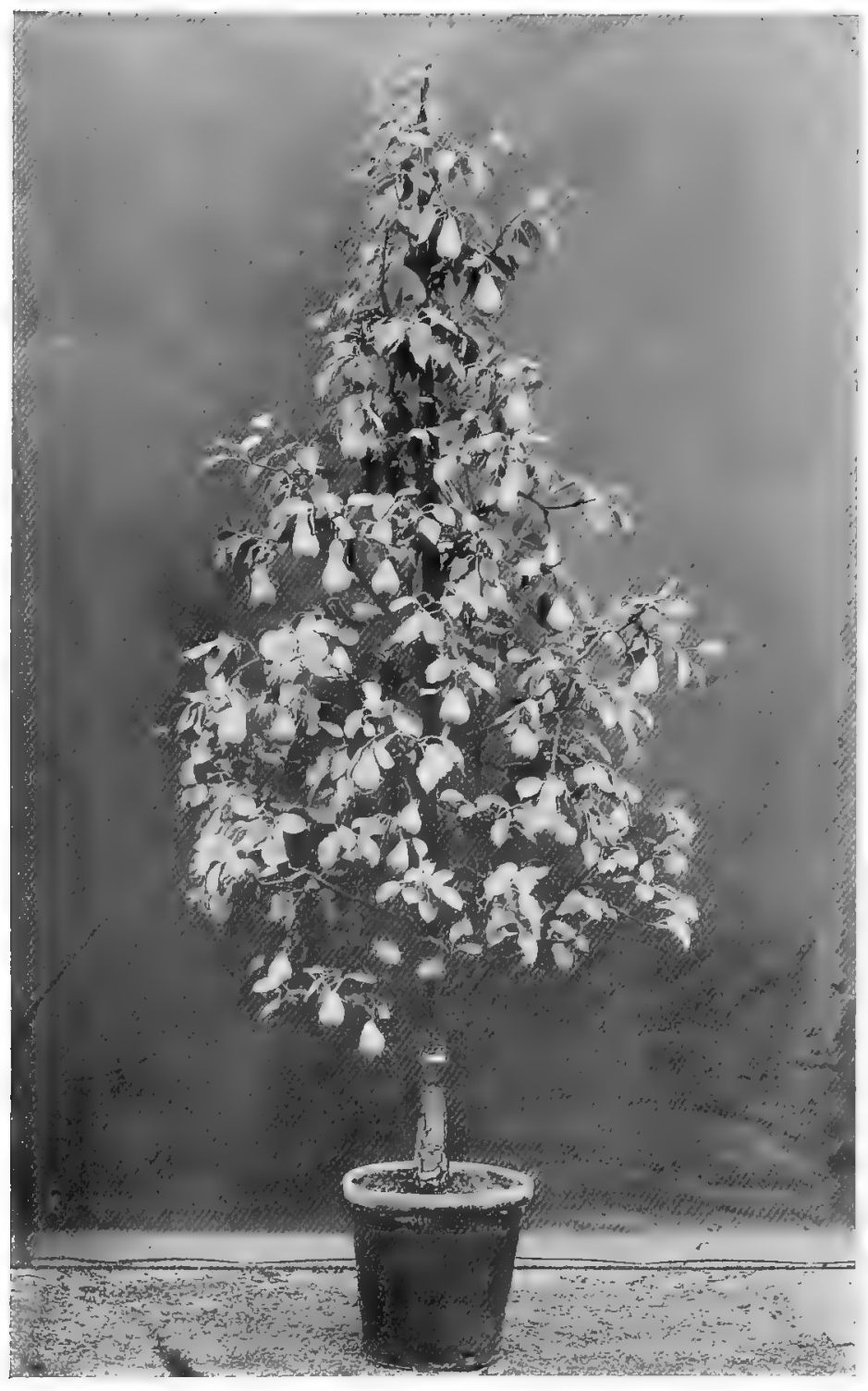

PYRAMID OF PITMASTON DUCHESS PEAR.

[To face p. x6. 

and plunged in the manner referred to in calendar of operations for June.

The wire house will form an excellent receptacle for them during the growing season, until the fruit is gathered. Then they can be placed outside again. After the plum trees have been potted, they can be placed inside the wire house and properly protected. In this way they will be safe from all attacks of the bullfinch until they are placed in the glass house again to flower.

$W$ ire houses are not a necessity, but are in every way decidedly better than any kind of fish netting that can be used, and being an up-to-date structure, I have no doubt that there are many people who will use them. Having used them myself, I can testify as to their value. I would advise any one, who can afford the outlay, to try them.

Many people are very sceptical with regard to the value of an enclosure of wire-netting, whether in the form of a house or otherwise, as they have been led to believe that they are detrimental to the well-being of the trees. Some persist in saying that the birds must not be shut away from the trees, or they will become so infested with insects as to do little or no good. This is simply a delusion.

If the instructions given be duly followed, the 
problem will easily be solved. 'The trees will be placed under glass during the flowering stage, and it is at this period, and in the first stages of growth, that the trees are liable to attacks from various kinds of insects. The work of the birds will therefore have to be substituted by artificial means, viz. by fumigating or by using an insecticide for insects, and remoring all caterpillars by hand.

By way of comparison, it should be borne in mind that trees, when grown absolutely under glass, are shut away from the birds, and if the wire enclosures cannot be fumigated, the aphides (whenever they appear) can be easily destroyed by the use of an insecticide, which can be applied by a sprayer or a small brush.

WATER. - Water is an absolute necessity for plant and tree life. Although it may not appear that the construction of houses has much to do with the water supply, yet the two are really very closely associated with each other. When building a house, it should always be borne in mind that rain-water is better than any other. more especially for syringing the trees, and also for watering, should the supply be sufficient. It is an excellent plan to have a water-trough rumning all round the house and leading into a tank, and if this is inside the house, so much the better. 
However, if there should be any objection to the tank being inside, then it can easily be made outside, in close proximity to the house. Byso doing, all the rain-water can be saved, and put to excellent use. Where possible, and where one has the high pressure, i.e. a tank into which the water is forced by mechanical or horse-power, the best plan is to have a pipe running through the house, with hydrants, to which the hose can be fixed. But where this cannot be done, and where the water has to be supplied from the main (or waterworks), I would strongly advise a separate tank for the reception of this water. It is best to allow the water to run in the tank a few hours before it is to be used. By so doing, the water is not so cold when used as when direct from the main.

This water can be used for watering the trees only, using the rain-water for syringing. Tanks can easily be made by digging a hole of the required size ; then bricking it in, and covering the bricks with a good thick layer of cement. If the tank is inside the house, it is best domed over and covered with boards, simply leaving a sufficient space for dipping. By so doing, more space will be available for the trees.

Cost of CONSTR LCTION. - With a view to assist those who may decide to build a house as per plan, I have consulted a professional builder, and 
he has furnished me with the following valuable information.

The cost of erecting a house of the same dimensions as per plan should range from 20 s. to 25s. per foot run. This will not include the heating apparatus, as that will be a separate item. The building materials for the house should consist of the following :- -

Bricks-Grood stocks.

Wood-The ordinary horticultural deal.

Glass-The 21-oz. (squares 20 ins. $\times 15$ ins.).

Being no expert on building matters, I can give no guarantee that all builders will be prepared to erect a house at the price quoted, nor do I hold myself responsible in any way for the estimate given; but I am fully prepared to say that no house of this description should exceed the maximum of 30s. per foot run. It is no uncommon thing for large prices to be charged for building houses, so that I trust the information here giren will serve as a rough estimate and guide to those intending to erect such houses. 


\section{CHAP'TER II}

THE FCRNISHING OF THE HOUSE

Number of trees required-Arrangement of the trees-Beds and borders-The need for separate compartments.

The number required.-The most important point to be considered in furnishing a house with trees in pots is to know the proper number required and the distance they should be grown apart.

As before stated, the span-roofed house is decidedly the best, and assuming the house to be $14 \mathrm{ft}$. wide, there will be sufficient space for a border on each side of a centre path, each border being $5 \mathrm{ft}$. wide, leaving $4 \mathrm{ft}$. for the path; and on each border two rows of trees can be grown $4 \mathrm{ft}$. apart if arranged in angles. The front row should start by allowing a space of $2 \mathrm{ft}$. from the end of the house, and the back row should start $4 \mathrm{ft}$. from the end of the house. This would bring them into the angle arrangement. (See diagram.)

The length of the house will now decide the 
number of trees required to fill it; and, as before mentioned, the height of the house will decide the form of trees.

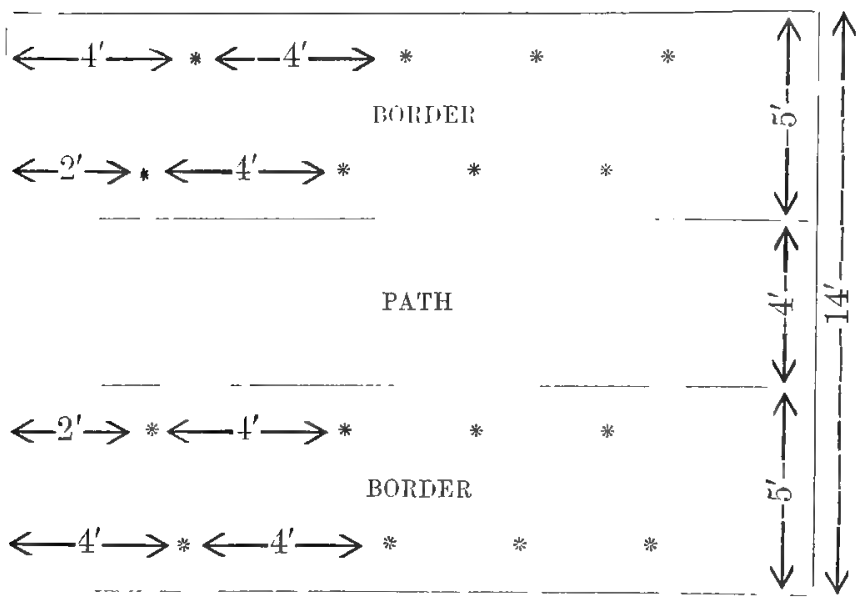

Each star represents a tree.

The above-mentioned house is only what may be considered a small one. A good class of house, which I strongly recommend, is one $18 \mathrm{ft}$. wide, $5 \mathrm{ft}$. high at eares, $10 \mathrm{ft}$. high at apex, and any length. (See plan.)

This is certainly a most useful house, and the best way of utilizing it is as follows: Have two side borders, each $7 \mathrm{ft}$. wide, and a centre path, $4 \mathrm{ft}$, wide.

This will allow a space on each border for three rows of trees. The first or front row might 


\section{I] TREES ON THE BORDERS}

be pyramids; the second or middle row halfstandards; and the back row bushes, as there will be ample room for each form of tree for several years.

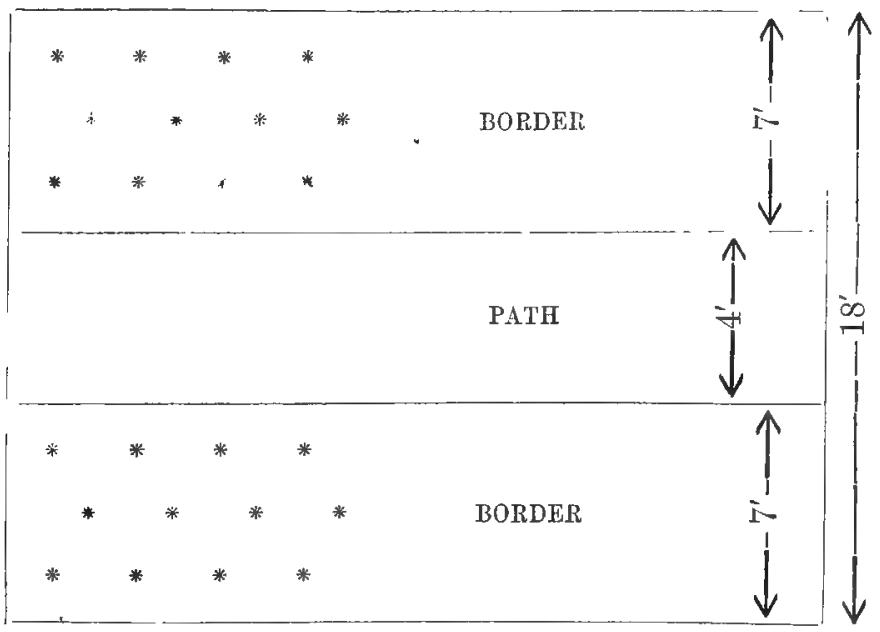

'The above diagram will illustrate the arrangement of trees on the borders. It will be noticed that the front and back-rows will be straight to each other, and the row in the midde will bring all into angles. The front and back row should start $2 \mathrm{ft}$. from the end of the house, and should be $4 \mathrm{ft}$. from tree to tree, leaving a margin of $2 \mathrm{ft}$. at the other end of the house.

Where larger houses are preferred, the same rule will apply with regard to distance from tree to tree, viz. $4 \mathrm{ft}$., with arrangement as before 
mentioned. It would, however, be much better if there were two paths instead of one in large houses, the paths being either $3 \mathrm{ft}$. or $3 \mathrm{ft}$. 6 ins. wide.

'The following dimensions and arrangements would form an ideal house. Length, $50 \mathrm{ft}$. to $100 \mathrm{ft}$., * or $150 \mathrm{ft}$., or $200 \mathrm{ft}$. ; width, $24 \mathrm{ft}$. ; height at eaves, 5ft. 6 ins. ; and height at apex, $12 \mathrm{ft}$. 'There would be ample space in this house for three borders, viz. two side borders and a centre bed each $6 \mathrm{ft}$. wide, and two paths, each $3 \mathrm{ft}$. wide; thus-

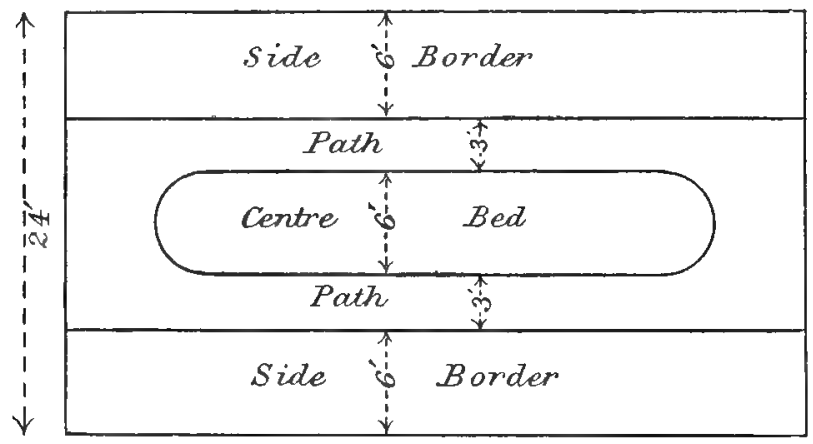

The side borders would be best deroted to halfstandard and bush trees, whilst the centre bed should be for the growth of pyramids only.

The arrangement of trees for this louse should be as follows. Let there be two rows of trees on

* A house of $100 \mathrm{ft}$. length would meet the ordinary requirements of any private family. 
each side border, viz. one row of bushes and one row of half-standards. These should be $4 \mathrm{ft}$. apart, and grown in angles, as mentioned on p. 22.

No hard-and-fast rule need be laid down as to whether the bush trees or half-standards shall occupy the front or the back row of the side borders. It will be better for the grower to decide this point for himself. I have frequently seen excellent results where the bush trees have occupied the front row, whilst the half-standards have grown in the back row. Probably some readers will say, "Surely the tallest trees should have the tallest part of the border." Granted; but there is also a great advantage in growing the halfstandards in the back row, with bushes in front. 'I'he low (or bush) trees, being in front, will allow the sun to shine over them on the half-standards, and this will assist greatly in giving colour to the fruit on these trees. Again, the pyramidal trees growing on centre bed will gain the advantage of much more light and sun, which will be especially beneficial to their bases. I must confess I am much in farour of this arrangement.

The centre bed of pyramidal trees should always have a margin of 5 or $6 \mathrm{ft}$. from the doors at each end of the house, as shown on diagram, p. 24 .

As some people may prefer growing their trees 
more ornamentally than others, I will give three methods of utilizing the centre bed.

First method.-A centre row of trees, $6 \mathrm{ft}$. apart, and a tree on each side, in angles; thus--

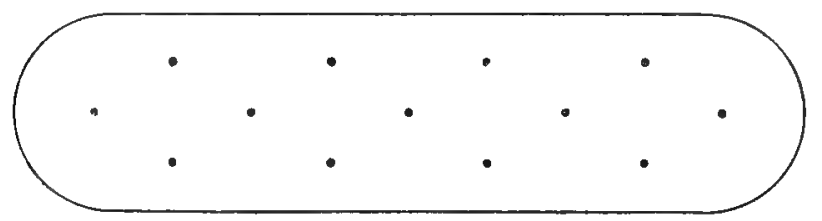

Second method.-C'Two rows of trees, $5 \mathrm{ft}$. apart, in angles; thus-

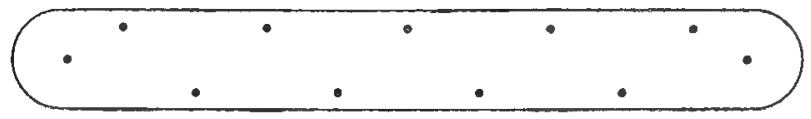

Third method.-One row of trees, $4 \mathrm{ft}$. apart ; thus-

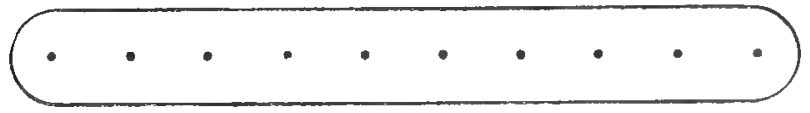

The first method should be adopted where space is limited; the second method where more ornamental trees are preferred; the third method where trees are intended to be grown as large ornamental specimens, for where grown in this manner there will be sufficient space till the trees attain the age of 20 or 25 years. If lean-to houses 
are used the arrangement of trees should be the same as that recommended for the side border of house $18 \mathrm{ft}$. wide.

BoRDERs.-A few remarks with regard to borders and beds, and their composition, will probably be appreciated. An elaborate border is quite unnecessary. The use of fancy tiles, cement, concrete, or even shingle, should be avoided The best border is one composed of the common soil over which the house is built. 'The only thing necessary is to measure out the borders and path (or paths) to their proper size, then remove the surface soil of the borders to the depth of about 3 ins., replacing it with coarse cinder-ashes. 'Take care that the rough ashes are at the bottom, with smooth or fine ones at the top. By so doing, the surface of the borders can be easily kept clean by being raked over. It is a good plan to run a roller over these borders a few times to make them fairly solid.

There is no objection to the use of edging tiles round the borders, as their use would tend to beautify the house. The paths should be composed of either fine gravel, concrete, or cement, whichever be preferred.

Where lean-to houses are used the arrangement of trees should be the same as recommended for the side borders of span-roof house, viz. half-standards 
and bushes, unless the house is a high one, and then a row of pyramids may be included, as mentioned elsewhere.

ThE NEED FOR SEPARATE COMPARTMENTS.Peaches and nectarines are probably the leading fruits grown in pots. Some people are very partial to apricots, though I have never found apricots to be so satisfactory as the former fruits. However, the inclusion of the apricot is optional. During recent years the best varieties of dessert cherries, plums, apples, and pears have also been grown with excellent results, especially cherries.

It would not be prudent to attempt to grow all kinds of fruitsmixed together in the same house. Nevertheless, the whole may be grown under the same roof if the following advice be acted on. Let the house be partitioned off to the extent of half, or two-thirds, of it, in which to grow peaches and nectarines. The remaining portion can then be utilized for growing cherries, plums, pears, and apples, if required.

The south, or warm end, of the house should be devoted to peaches and nectarines. The cooler end would be better adapted for the hardier fruits. If only peaches and nectarines be required, then no partition will be necessary.

The reasons for recommending a division of 
a house are these. Peaches and nectarines will succeed well if grown under the same conditions. During the growing period, and, in fact, until the fruit commences to ripen, it will be necessary to use the syringe liberally to check the "red spider," etc. ; but if cherries and plums are introduced into the house, they will ripen their fruits, especially the cherries, much earlier, and as soon as the cherries begin to colour, syringing should be discontinued, or the water would cause much of the fruit to crack and spoil.

Then with regard to plums: if these are syringed when the fruit is ripening, much of the fruit will crack, and the beautiful dense bloom will be destroyed. 'The preservation of the "bloom" on plums is quite as important as in the case of grapes. Hence the reason for advising partitions, or a partition in a house, as this will be most adrantageous.

As a substitute for syringing when the fruit is ripe or ripening, a frequent damping of the borders and paths of the house may be carried out, especially where all "stone fruits" are grown.

The partition referred to should correspond with the ends of the house as near as possible. In large houses, where two paths are used, it will be best to have two doors the width of each path. Only a small amount of brickwork will be needed, 

in fact three courses of $4 \frac{1}{2}$-in. work above ground will be ample. The wooden sill, $4 \frac{1}{2}$ ins. wide, will rest upon this, and, if possible, the remaining portion of the partition should be glass, as before mentioned. 


\section{CHAP'TER III}

CULTURAL DETAILS

The forms of trees-Potting-Soil-Potting-hook and Prong-Perforated pots-Method of forcing-Pruning-Pinching-Hidebound trees-Surface dressing-Number of fruits on a treeCost of trees-Longevity, etc.

TIIE ForM of TREes RECOMMENDED.-'The best forms of trees to grow, especially for amateurs, are bushes and half-standards. By these are meant trees on clear stems, ranging from 9 to 12 ins. (or even a little more) for bushes, and from 18 to 24 or 30 ins. in height for half-standards, according to the height of the house. A clear head space of at least $\mathbf{2} \mathrm{ft}$. should always be allowed for the growth of the trees.

Where space permits, and ornamental trees are required, the pyramidal trees will be the best for the purpose, because there will be no barren stem, the trees being furnished with foliage and fruit from the base to the crest. Nothing can be more beautiful than a pyramid peach or nectarine tree, either when in flower or when corered with fine-coloured fruits. This form of tree is well 
adapted for growing in the centre bed of houses, or where there is plenty of space to allow for their upright growth.

It is only right to state that pyramidal trees require more skilful pruning and management to keep them in good form. However, they will amply repay the grower for all the care bestowed upon them.

Generally speaking, stone-fruit trees are all inclined to bush or head growth. There are some varieties, though, which form handsome pyramids, and these can always be selected for that purpose. Apples and pears are easily grown as pyramids. They also grow well as bushes or half-standards. Cherries (though one of the best of fruits) are undoubtedly the most shapeless growers of all fruit trees in pots. I can well understand a person purchasing a cherry tree in pot, and, on the receipt of the same, expressing his amazement at its appearance; but this is in the barren stage of the tree. If patience be exercised in the matter, there is an agreeable surprise in store; for when the tree comes into flower, and later on is corered with foliage, the appearance of the tree is decidedly better. 'The quality and excellence of the fruit should be the first consideration, and not the shape of the tree. These trees are grown as pyramids and bushes, as some 


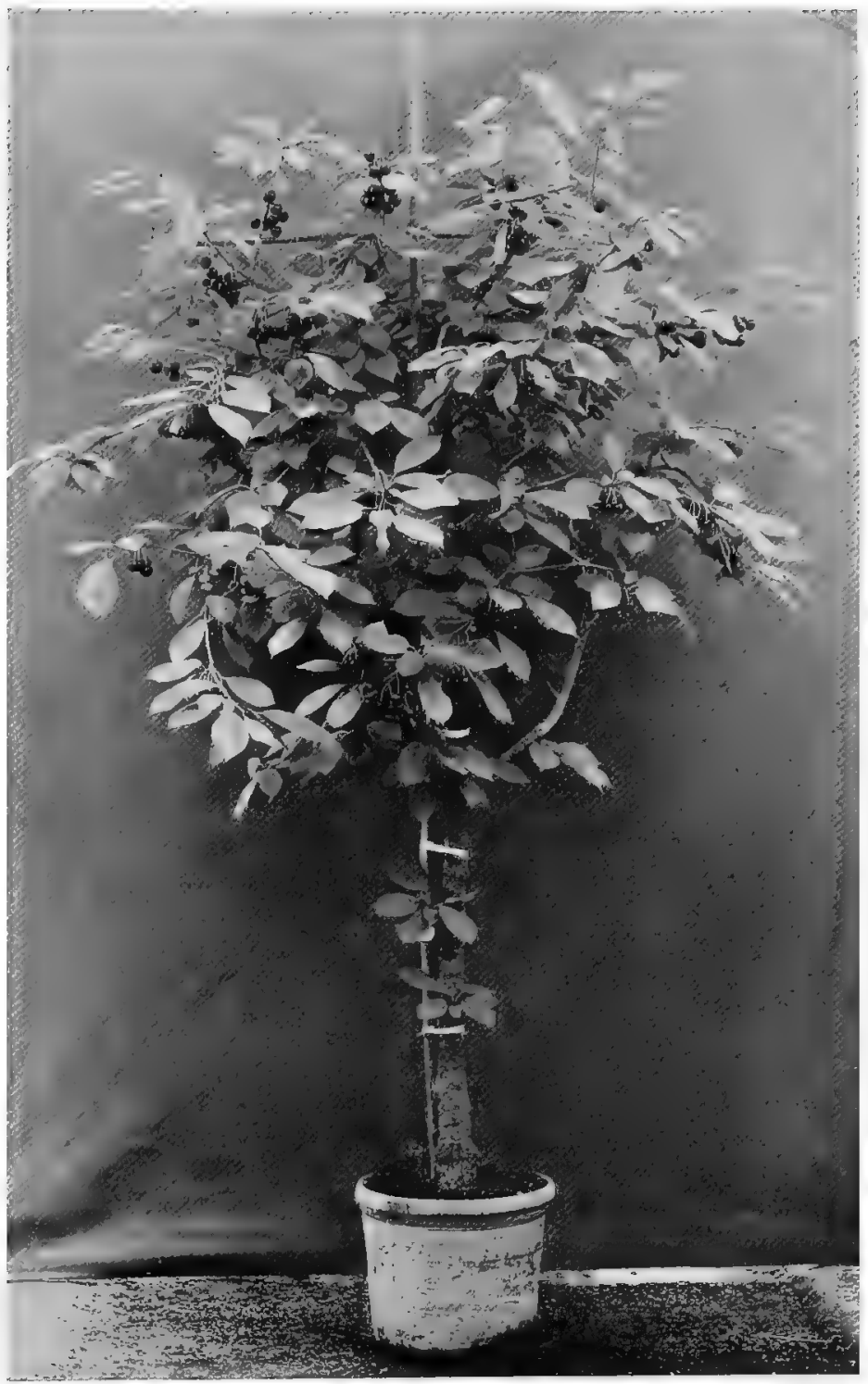

HALF STANDARD OF EMPEROR FRANCIS CHERRY.

[To face $\not p .3^{2}$. 

varieties are best adapted for one form and some another.

With regard to plum trees, the pyramids are most to be recommended, as they grow well in that form, and are most ornamental in appearance.

Potering of 'TRees, AND soli، to Be rsed for PotTix(1.-- The potting of trees is a very important operation, and should always be done at the proper season of the year. Where trees are intended for early forcing the potting should take place from the middle to the end of September. Where trees are not forced the potting should be done from the second week in October to the end of same month, or by the first week in November. There is no necessity to wait till the trees have shed all their leaves; for if some of the leaves are on the trees-more especially peaches and nectarines - they will be of more good than harm.

The trees should always be syringed two or three times daily, after being potted, until they shed all their leaves. This spraying will have the effect of nourishing the fruit-buds sufficiently till the roots commence to work in the new soil. In potting the soil must of necessity be disturbed, and a slight check is thus given to the roots.

The operation of potting should be thus carried out. Commence with the earliest peaches and nectarines, follow on with mid-season, and then 


\section{4}

with the late varieties. Where apricots are grown these should be potted next. Continue with cherries, then plums, then pears, and, last of all, apples.

Sorl.-One of the most essential points for successful pot culture is the selection of good soil. This should consist of a good fibrous loam, fairly heavy, but not clayey - such as the top spit $(2,3$, or 4 ins. thick) from any good meadow would answer admirably. Some good decayed stable manure should be added to this, and, if procurable, a little old rough mortar or chalk may be added. Should chalk be used, it must not be crushed too small, but used in small lumps about the size of an acorn or small walnut.

The soil should be made up in the following proportions: loam, two-thirds; manure, onethird; mortar or chalk, a small quantity; or, in other words: loam, two cart-loads; manure, one cart-load, of equal quantity per load; mortar or chalk, half a wheelbarrow load to each cart-load. The use of mortar or chalk is beneficial to all stone fruits, as it will assist the fruit very much during the stoning process. Mortar or chalk is. however, not absolutely necessary if good loam be used, though I should always use a little if I had it.

The use of peat or of rery light sandy soil, 
must always be aroided, as they are absolutely useless.

I have frequently been asked the question, "What is loam?" I Joam is one of the principal soils used in gardening operations. Gardeners will easily understand the expression, but as many amateurs and the inexperienced will not, I would advise these, when ordering loam, to use the expression, "fibrous loam," as horticultural sundriesmen will easily understand what is required. Always be explicit, and ask for heary, or moderately heavy, and not light loam.

It is always best, where possible, to store the soil some time previous to its being used. Dig the loam (or procure it) some six, nine, or twelve months before using, and place it in a heap, turves downwards, so that it may become what is commonly termed "mellow." Then secure some good stable manure containing plenty of horsedroppings, and place it in a heap. This should be done two or three months before it is used. Turn the manure over once or twice to assist it in decaying, for by so doing it will be far better for use.

With regard to soil, it is the best plan to prepare sufficient for each year's work only where one has plenty of soil at hand, unless a good bargain can be made in the way of loam. Then, 
if of good quality, procure as much as possible, as it will always keep. Soil is best when mixed a week or two before using. If it can be placed under cover, either in a potting shed or glass house, so much the better. During the time mentioned the soil should be turned over twice, so that all the ingredients are well mixed together.

The soil should not be cut into small lumps or powder, but used in the form of lumps about the size of a cricket ball, or even a little larger, as the roots will adhere to them far better.

Pots.-As pots play a fundamental part in pot culture, I wish to impress upon all readers the importance of their use. Never use pots of too large a size, or the result will not be at all satisfactory. The 11-in. or 13-in. pots will be large enough for the trees generally supplied by nurserymen. If, a year later, a few of the trees have made more growth than others, and have but little soil to grow in, then these might be potted in 15-in. pots. The remainder of the trees can be repotted into the same pots as they grew in the year before.

The 15-in. pots will be large enough for trees up to the age of eight or ten years. The age of a tree is easily arrived at, as they are generally two, three, or four years old when supplied. Of course, as trees grow on for a greater number 


\section{III] IMPLEMEN'TS FOR POT'TING 37}

of years, it will be necessary to transfer them to 17-in. or 19-in. pots, as they will not be too large. Large pots, however, must never be used at the first onset.

Pots are decidedly better than tubs, and I advise the use of them, for experience is the best teacher. Always use clean pots and crocks in

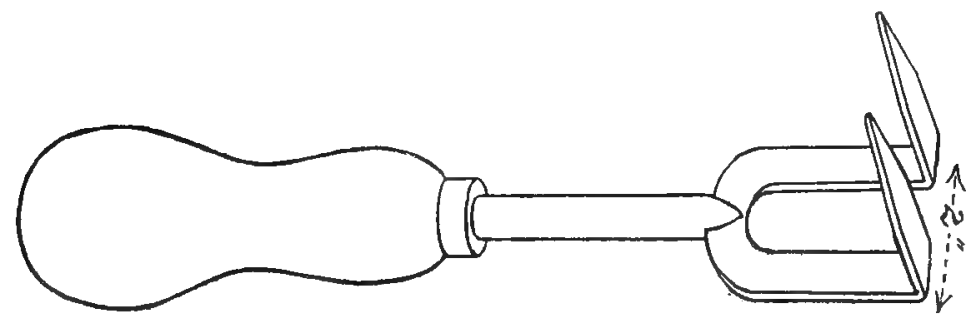

$\prec--$ Handle 5 inches-- $\nmid<-\cdots-$ Hook 5 inches $-\cdots$

Handle 8" Prong 12" potting. If new pots are not used, the old ones can easily be washed. Take care to remove sufficient old soil from the roots. This will generally amount to one-third, or rather more.

There are two very useful implements which I would recommend to be used when potting, viz. a small hook and an iron prong, as per illustration.

The iron should be round, and $\frac{1}{2}$ in. in diameter. 
'These are very inexpensive, and can be made by any blacksmith.

The hook should be used for removing the old soil from the ball.' 'The best way to do this is to release, as far as possible, the roots running round the ball of soil, and then comb the roots downwards until sufficient soil has been removed.

The prong will be useful for remoring the soil round the rims of the pots, and should be worked round and round inside the pot. By so doing it will not break the pots.

'The diagram is intended to represent the pot, and the dotted lines are sup-

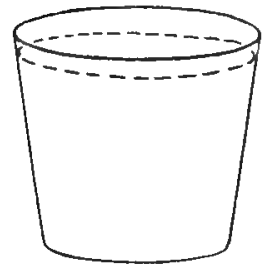
posed to show the course of the prong.

If the surface soil, in large pots, is moved to the extent of 2 or 3 ins. in width and 5 or 6 ins. in depth, and the pots placed in a sloping position, the trees will leave the pots quite easily. When the soil has been remored from the ball, and the tree ready for repotting, any long roots found may be shortened about one-third of their length.

The trees should not be potted too deeply, but only sufficiently so to ensure that the surface roots are just covered.

A flat rammer, about $\frac{1}{2}$ in. thick, 2 or $2 \frac{1}{2}$ ins. 
wide, and long enough to reach the bottom of the pot, should be employed. This sort of rammer will be best until there is a space for a round rammer, which should be 2 ins. thick, and 12 to 15 ins. long.

A small quantity of soil should be used each time, and the soil rammed firmly and evenly.

After the trees are potted they should be watered occasionally until the middle of Norember if the weather is mild, and not frosty. They should then be placed in their winter quarters, and water ing discontinued.

Annual potting, or, more correctly speaking, repotting, is the best practice with trees growing in 11-in. or 13-in. pots; but where larger pots are used, 15,17 , or 19 ins., unless the tree is very large, repotting need only be performed oncein two years. In the alternate years the trees may be top-dressed, i.e. the old soil may be removed, with the aid of the prong before mentioned, to the extent of about one-third of the diameter of the ball, and from 4 to 6 ins. in depth, the space being refilled with new soil. Care should always be taken in repotting or top-dressing to ram the soil firmly.

Where trees are surface-dressed in summer, the roots will undoubtedly fill the surface-dressing with small fibrous roots. When the trees are repotted in the autumn these small roots may all be 
taken away to the level of the top of the pot, as they are only annual roots. It is a inistake to bury all these roots; they should be cut away, or the trees will soon require very large pots.

This is a simple, but so important a matter, that it should be strictly attended to.

The PERFORATED POT.--This is a pot which is sometimes used to adrantage. The size is the same as that of an ordinary pot, only it has perforations in the side, instead of being solid and whole. The perforations should be about 3 or $3 \frac{1}{2}$ ins. below the rim of the pot, and about 2 ins. in diameter. 'The advantage derived from the use of these pots is economy in potting and watering, and the promotion of additional vigour to the trees; for the roots of the trees pass through the perforations into the surrounding soil. Of course, where these pots are used, repotting is seldom needful, but it is quite necessary to renew the soil in the border in which the perforated pots are plunged. The trees should be taken out of the border each year, and the large roots cut away, and then the soil in the border should be dug over, and the pots plunged again. 'The composition of the border should be the same as the soil for treen in pots. The trees should then be plunged up to the rims, and watered whenever necessary. Peaches, nectarines, and apricots should be grown in the 


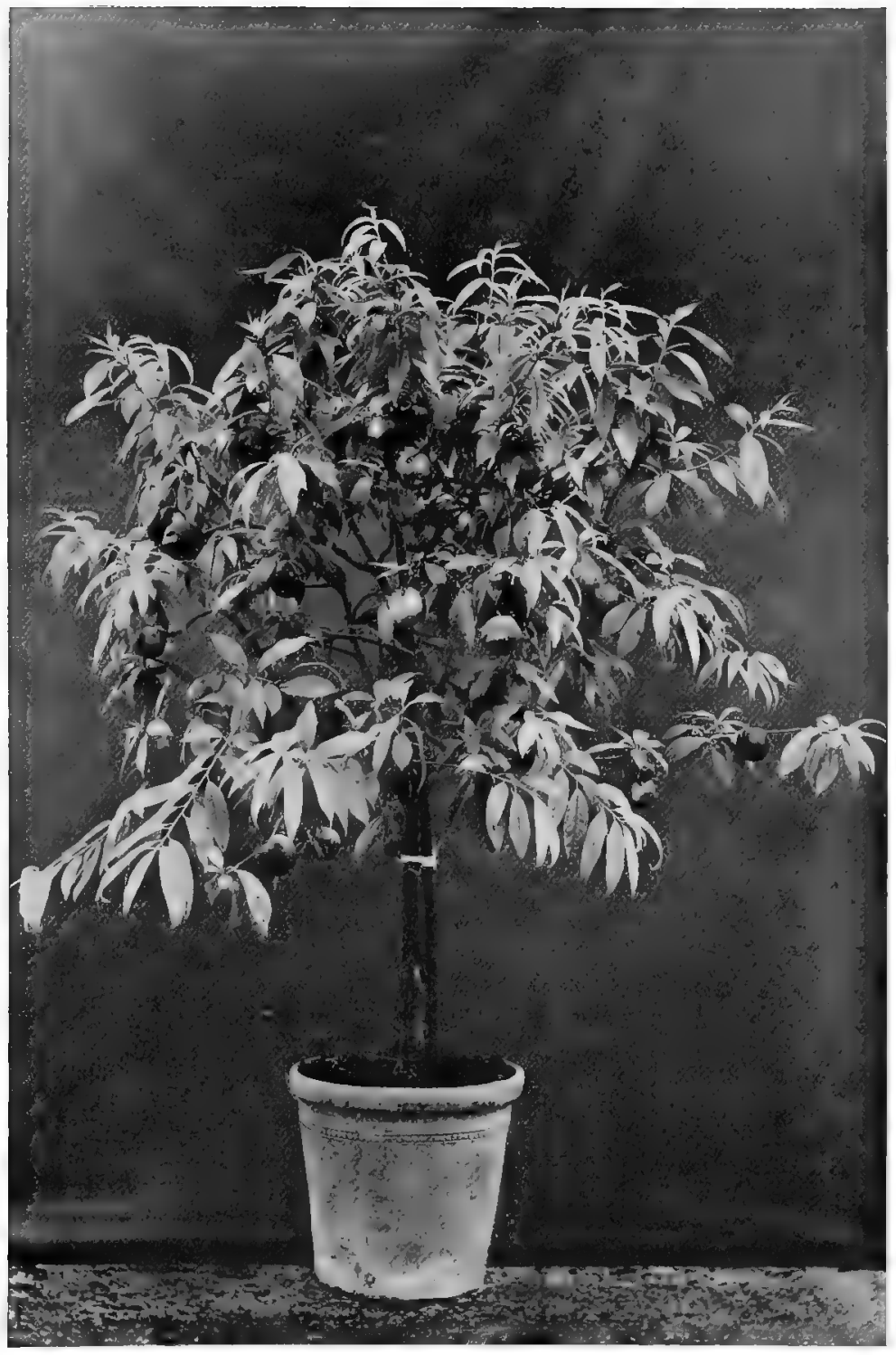

BUSH OF LORD NAPIER NECTARINE.

[To fuce p. $4^{\circ}$. 



\section{III] METHOD OF FORCING TREES 41}

ordinary pot-not in the perforated-and they should be grown on the surface, and not plunged. Where large cherry trees are grown in pots the ordinary pot may beused, plunged to three-quarters of their depth. 'This will have the twofold advantage of economizing watering, and will give additional head-space. 'The ordinary pot should also be employed for apples, pears, and plums, but these, if grown out-of-doors, should always be plunged (see p. 92).

Where perforated pots are in request, it is best to have them made to order from any pottery.

Method of Forcing trees. - The calendar of monthly operations to be given in a subsequent chapter is intended to apply to the cool or unheated house only, but as many people force their trees, I will give a brief outline of the treatment to be adopted. The trees should be potted between the middle and end of September, and, where possible, placed in the house and watered when necessary, and syringed occasionally. The house should be freely ventilated all day, and even at night, should the weather be warm. This treatment may be continued until December.

Assuming that the trees are required to ripen their fruits by the end of April, or early in May (I am speaking of peaches and nectarines), they must be started during December. The precise 
date of the month will have to be decided by the locality, but by way of illustration, for the south of England about December 20 is the best date for starting the fire. Use only gentle heat to begin with, and spray the trees occasionally, as this will assist the blossom buds to open. As the trees come into flower give as much air as possible at this season of the year, for it must be borne in mind that air is an essential for the setting of these fruits. As there will not be any bees about at this period, it will be necessary to use the artificial means of fertilizing the flowers described on a subsequent page. Watch the setting of the fruits, but do not attempt to hurry their progress by applying strong heat, as this would be fatal. A good and safe temperature is one ranging from $45^{\circ}$ to $50^{\circ}$ or $55^{\circ}$ Fahr., until the fruit is well set. As the fruit increases in size the temperature may also be gradually increased, say from $60^{\circ}$ to $65^{\circ}$ or even $70^{\circ}$ Fahr. with ventilation.

Give ventilation every day when the weather is favourable, but avoid admitting a strong or cold air, and especially so on the windy side of the house. It will be easily understood that the opening of the house will take place later in the day, and the closing of the house earlier than that recommended for a cold house. The syringing will probably be done in the morning only, but, as a substitute, the 
borders can be damped down in the evening. 'The thinning of the fruits, pinching of the trees, and watering, will be effected in the same manner as in a cold house, only it will be necessary to sometimes water the trees twice or thrice daily.

After the fruits have finished "stoning," an increase of temperature may take place, but $75^{\circ}$ to $85^{\circ}$ Falur. is far better than $90^{\circ}$ to $100^{\circ}$. An exccssive temperature only tends to premature ripening If a little night air can be given when the weather is warm, its effects will be beneficial.

After the fruits have been gathered, the best plan is to place the trees in a cool house for a time. At the end of May, or the first week in June, they may be plunged out-of-doors in the same manner as those from a cool house. 'Their latter treatment should also be the same.

The PRLNing of Trees.-Pruning is an operation which should always be performed judiciously. 'The "rule-of-thumb" system is frequently adopted, but does not always bring about good results. A careful study of the instructions and diagrams of trees here given will undoubtedly prove advantageous, and especially so to the amateur and inexperienced fruit-growers. In the first place, peaches and nectarines vary considerably both in habit and growth. While some rarieties form triple buds, i.e. three buds in one cluster, other varieties 


\section{FRUIT TREES IN POTS [CH.}

produce all, or nearly all, single buds. 'This is a matter of rast importance, inasmuch as the triple eyes contain both blossom and leaf buds, for in the majority of cases the centre bud is a leaf bud, and the other two buds, one on each side of the centre bud, are blossom buds. Now, these naturally form the best growers, and, if pruned with a little discretion, produce plenty of fruit spurs, and so give a good crop of fruit. With regard to the rarieties which form single buds only, it will be found that nine-tenths of these will be fruit buds, or, in other words, blossom buds, and no leaf buds will be formed except at the ends of the shoots. These varieties should always be grown in the form of bushes, or half-standards, as they never develop into an ornamental pyramid, whereas the varieties which form triple buds, with very few exceptions, are well adapted for pyramidal growth.

The pruning of all fruit trees, especially stone fruits, should always be done with a good sharp knife, not with scissors, for the cleaner the wound the quicker the healing. It is rery detrimental to the growth of trees when pruning is done in a reckless manner. Trees are too frequently cut in a jagged and cruel manner. In some instances spurs are left almost to the extent of an inch above the eye, and the result has been that the wood has died down to the eye, and in some cases below it. If 
the pruning had been done in a proper manner, the shoot would have formed a good "callus" where cut, and there would have been no dead wood.

'The manner in which the shoots should be prumed is shown in the diagram at $A$, whilst at $B$ the method of pruning to be avoided is illustrated.

It will be seen from these sketches that the
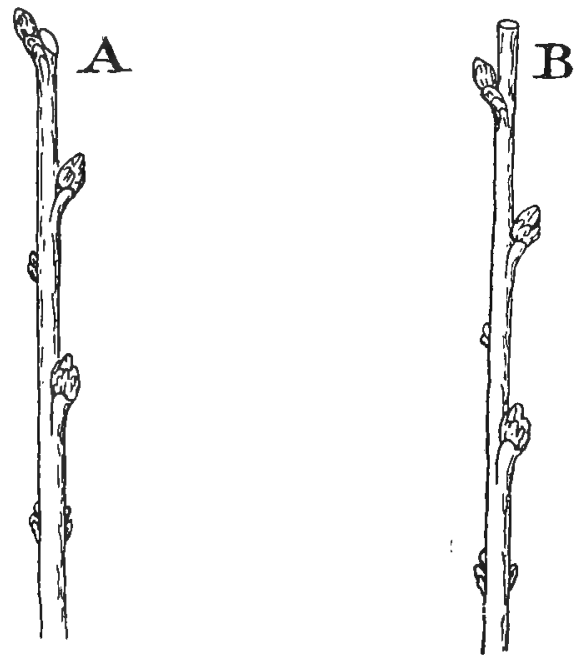

cut should be made in a sloping direction immediately above the bud or eye, so that the wound will quickly callus orer. 'The incorrect manner is to make a horizontal cut at some distance above the eye. 'The main object in pruning peaches and nectarines with triple buds is to thin out the shoots sufficiently to admit the light and air, and 
also to preserve a good-shaped tree. This can be done by pruning the tree into the required form; but, on the contrary, the varieties which produce single buds only should be pruned with a little extra care. Plenty of such shoots should be left unpruned even to the extent of a foot or so until the leaf appears. Then if these shoots can be brought nearer home, so much the better. Always endeavour to preserve a succession of shoots for the following season (see diagram).

The accompanying diagram is intended toillustrate the pruning of both bush and half-standard of peach and nectarine, the difference in the two trees being simply the height of stems. The tree in either case will be in the form of a round head, and it is a good practice to select sufficient outside shoots-and these should be $1 \mathrm{ft}$. apart, and not pruned, but allowed to bear fruit, so as to form an umbrella-like shape(see letter $a$ ). 'The small shoots in the intervals of these outside shoots should always be left unpruned, as they will replace shoots $a$ in the following year, and the umbrella form will be preserved. Shoots $b$, if the tree is a strong grower, should be pruned back to within 6 ins. of the small spurs $x$ in all cases where the shoots are in erect form. Should the tree be a weak grower, prune back shoots $b$ to 4 ins. The object in both cases is to induce the shoots to put forth more 
small spurs, $x$, as these undoubtedly produce the finest fruits. If the shoots of the tree should be rather thick, all such shoots marked c may be cut away. This constitutes a simple but good form of

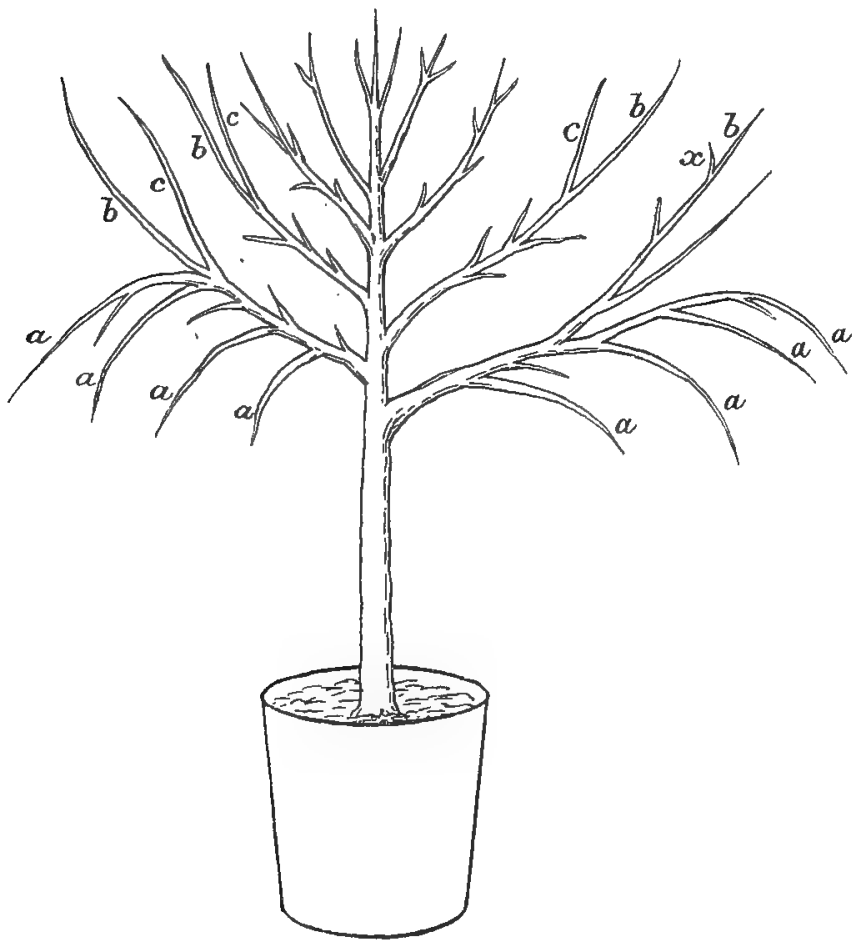

pruning for the bush or half-standard tree. This pruning will be done when the tree is commencing to swell its blossom buds, riz. about the middle of February. 
The diagram below is intended to illustrate a pyramid tree of peach or nectarine. The one

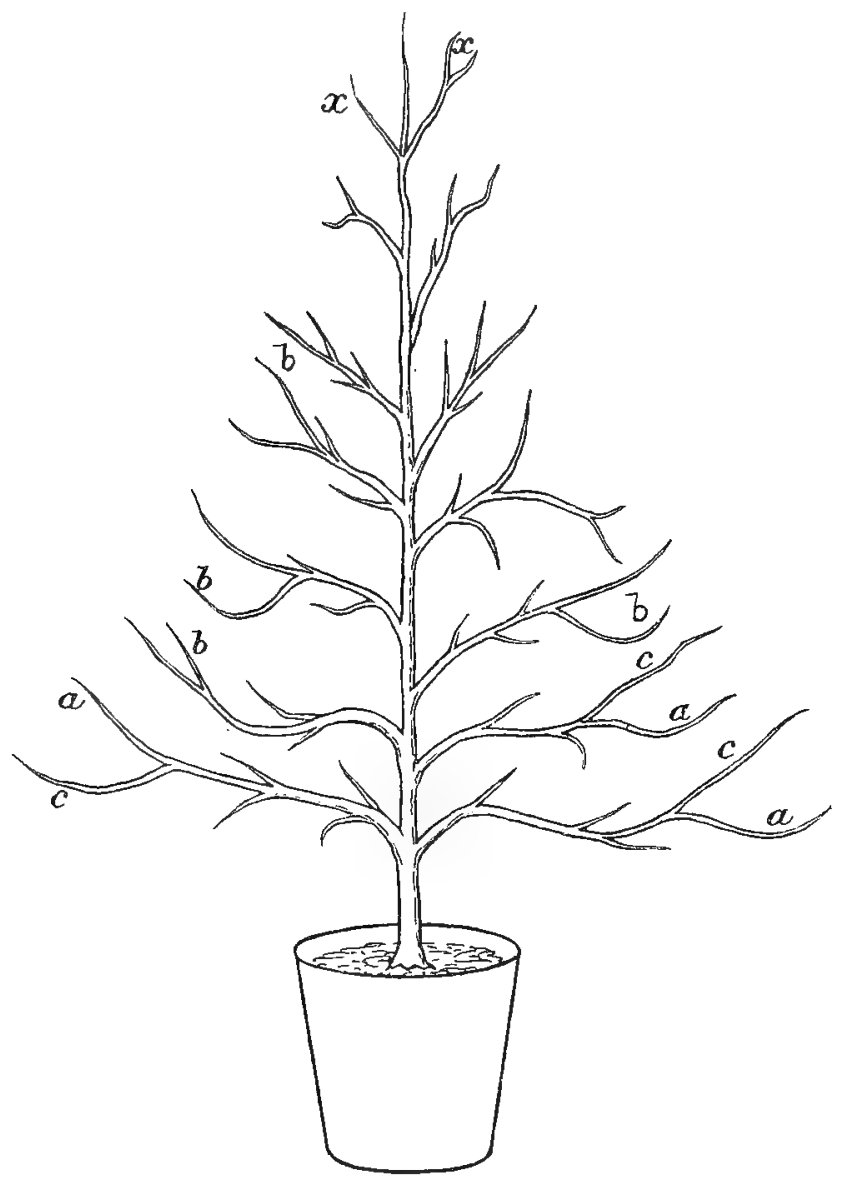

essential for this form of tree is the selection of the proper variety. 


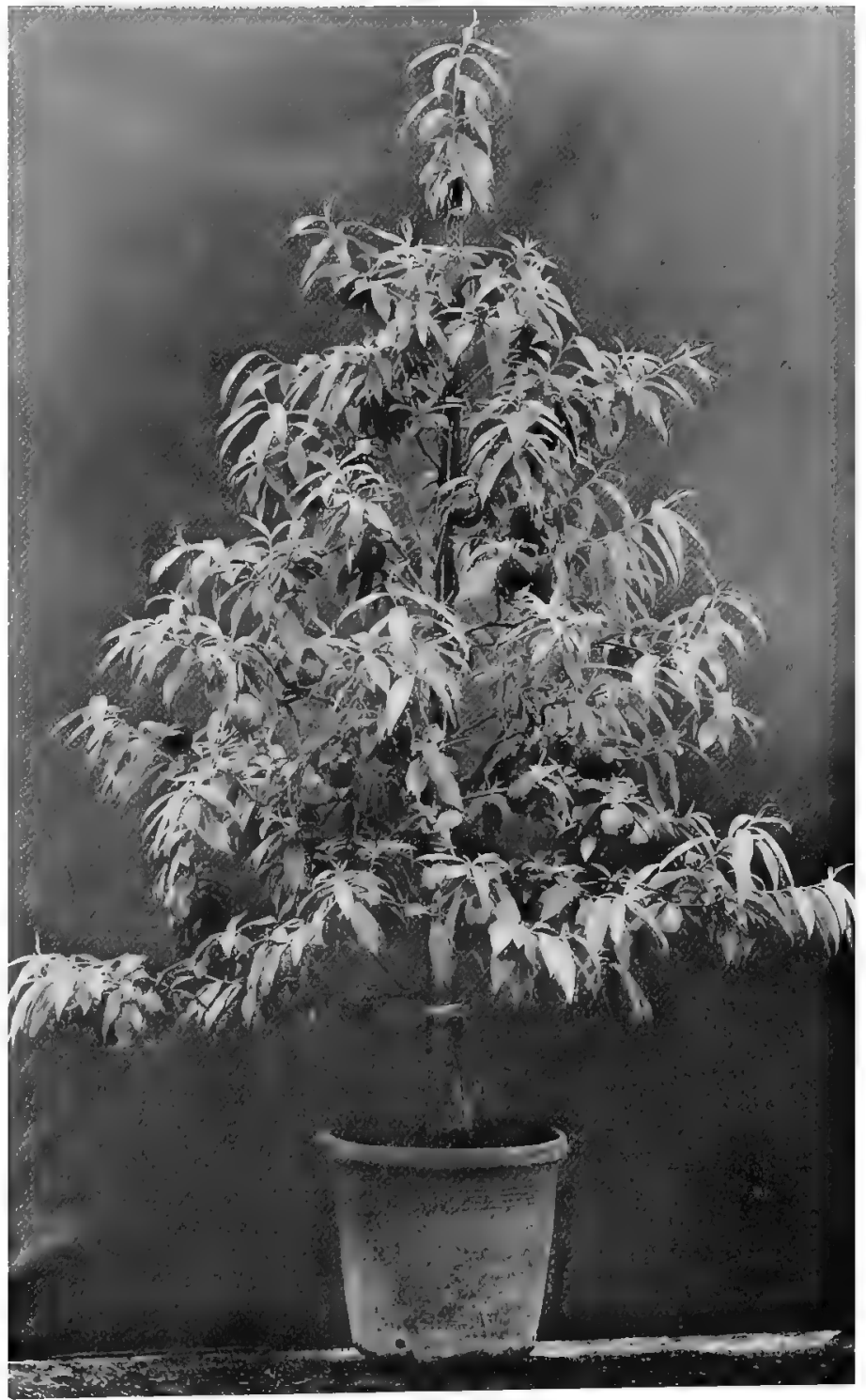

PYRAMID OF EARLY RIVERS NECTARINE.

[To face p. $4^{8 .}$ 

The base of the tree should always be preserved, and in the first place the shoots $a$ should be cut away, if not absolutely, at least to within three or four eyes; shoots $b$ should be removed in the same manner. If the leading shoots, $c$, are growing in the same proportion as in the diagram, they should be shortened a little. The same rule will apply to the whole tree, with the exception of the centre shoot. In many cases the centre shoots have a tendency to strong growth, and where such is the case they should be shortened back to a few inches, and replaced by a new centre. 'This is easily done with either shoot marked $x$. Should the shoot intended for the new centre be found a little stubborn, let it be treated gently, tying it up a little each time, until it reaches its proper position. 'l'o obtain a good straight stem, the centre shoot should be pruned the opposite side each year. All the little spurs should be left unpruned, and the strong shoots should not be pruned too severely, as this would only encourage a strong growth; but in the event of a very strong shoot presenting itself, it is far better to cut it right away. Very strong shoots are only deceptive, and give little or no fruit. The best sort of "wood" is that of the thickness of a small lead pencil, or even smaller, as the size of a small straw or telegraph wire. 'Thus it is best to preserve a 


\section{0 FRUIT TREES IN POTS [CH.}

good number of these shoots, and dispense with the larger ones.

A pricots generally form an abundance of triple eyes, in which case the only thing necessary is to prune the tree so as to form a good symmetrical

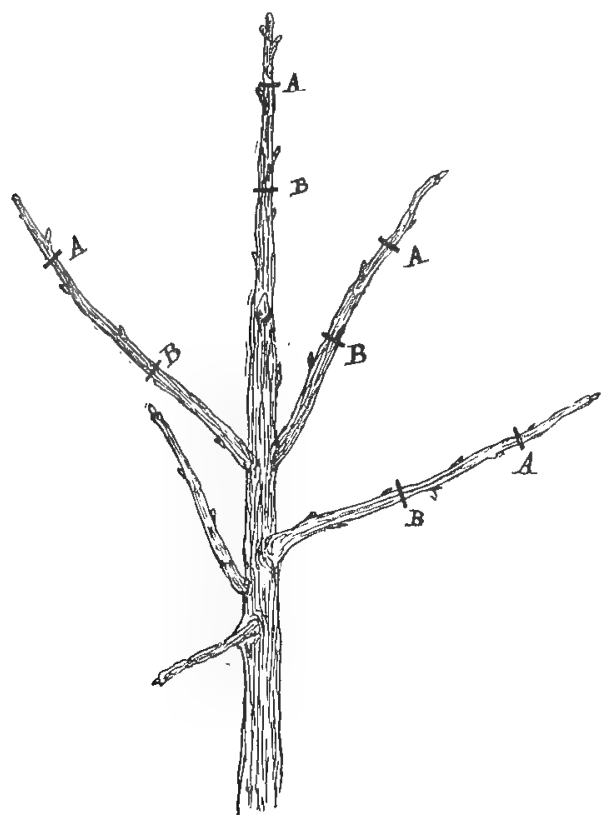

IPPLE: ANI) PlAAR (1).

tree. 'The best form to grow apricots is the bush or half-standard. 'They do not make good pyramids.

The following information will explain the roper routine of pruning other pot trees. Apples 
and pears are very similar in their growth and habits, and the method of pruning of the one may safely apply to the other. Some varieties grow more freely than others, and in consequence require more pruning, to induce them to form fruit spurs. The slower growing varieties require little or no pruning, sare the thinning out of a few shoots, should the trees become too thick. Fach of the diagrams are intended to represent a tree to illustrate the pruning of the apple and the pear.

Diagram No. 1 shows a tree that requires pruning. Diagram No. 2 (p. 52) shows a tree that requires no pruning.

It will be noticed in diagram No. 1 that there are three shoots growing from the stem and one centre shoot.

It must now be supposed that the tree is growing in an erect form.

The three shoots must be pruned back to letter A. 'The centre shoot must also be pruned back to letter $\mathbf{A}$, as this will cause the growth of other shoots to furnish the centre of the tree as it increases in growth.

In the event of a side shoot, i.e. a shoot growing in a horizontal direction instead of upright, the samediagram will illustrate the method of pruning. Each of the three shoots should be pruned back 
to three or four eyes, as they will form fruit spurs (see letter B).

'The leading shoot must not be pruned so closely, but only to the extent of one-third of its growth (see letter B on centre shoot).

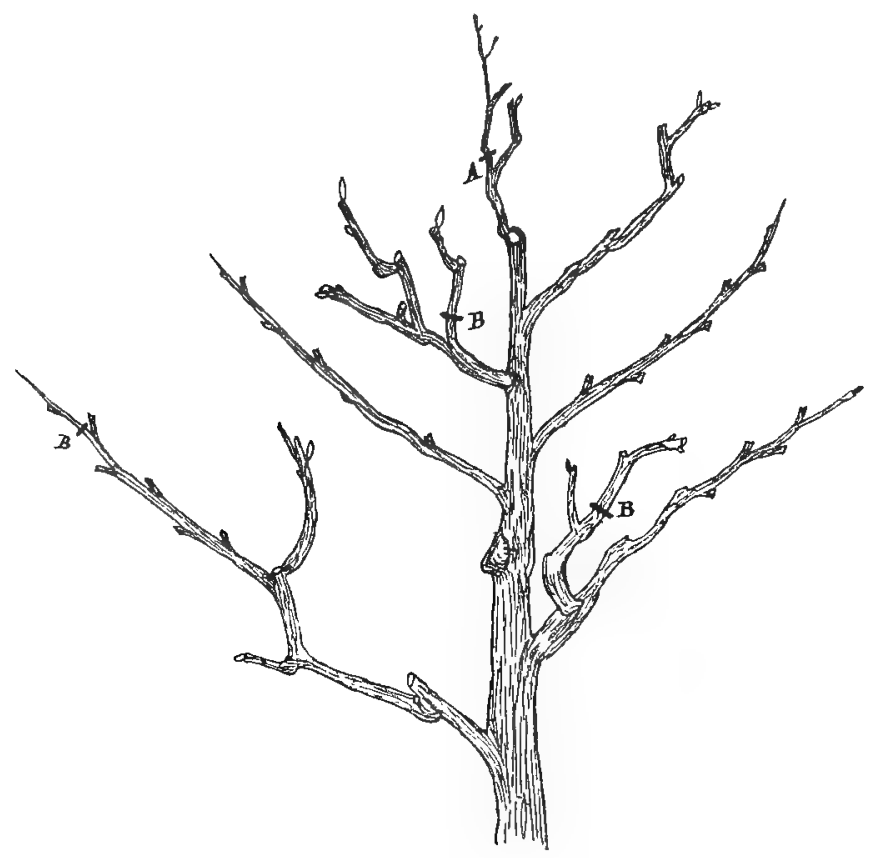

IPPJE AVI PEIR (2)

When pruning a side shoot, it is always the best plan to prune to an eye pointing outward, as this gives the shoot more room for growth, and thus avoids crowding. 
In diagram No. 2 the thinning out referred to can easily be performed by pruning back to any spur (see letter $\boldsymbol{A}$ ).

The only two cases where this will be needed is to give uniformity to the tree, and to thin out if too crowded (see letter B).

'The cherry and the plum are both stone fruits, and somewhat resemble each other, although they are not quite identical. However, the same rule of pruning will serve as a good illustration for both. The two diagrams show, one where pruning is necessary, the other where little or no pruning is required. Diagram No. 1 represents a freegrowing variety, where pruning must be performed. Diagram No. 2 represents a weaker growing variety, requiring little or no pruning.

In diagram No. 1 the tree is supposed to be a pyramid. The shoots Nos. 1, 2, 3, 4 should each be pruned back to the point indicated by letter A. Shoot No. 5 should be pruned more closely to form a fruit spur (see letter B). The centre shoot should be pruned back to letter $\mathrm{A}$, as this will induce the growth of a succession of shoots, and thus furnish the stem of the tree.

The double or forked branch $\mathrm{C}$ will serve to illustrate the pruning of any shoots growing from the principal shoot. 'These shoots are generally termed lateral shoots. In every case where such 
shoots have exceeded a growth of $2 \frac{1}{2}$ or 3 ins., they should be spurred back as before mentioned (see letter B).

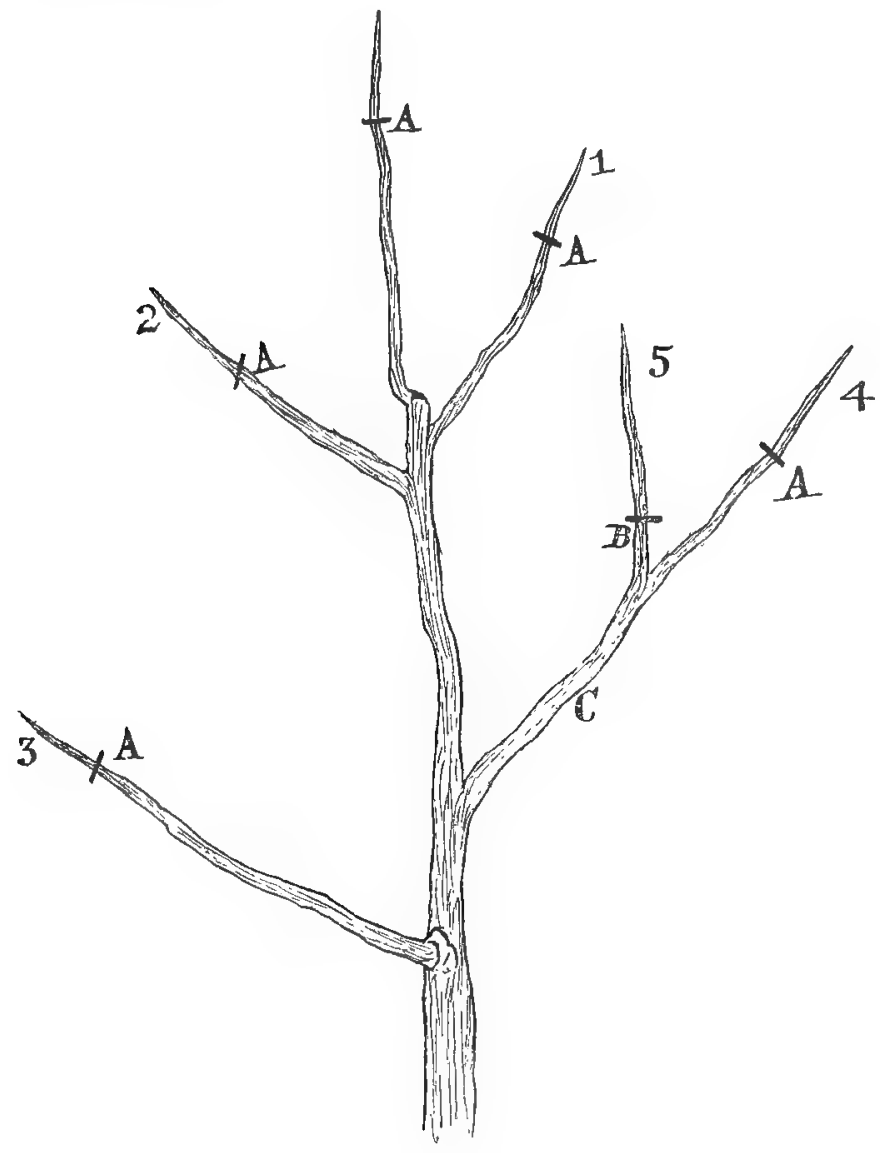

hiblut AND PIAM (1). 
'This rule applies to all branches, but not to the centre of the tree.

In diagram No. 2 it will be noticed that the tree has made no strong shoots. 'The whole of the growth is composed of fruit spurs, hence the necessity of showing the two different methods of treatment.

As nature has prorided the fruit spurs, there will be no cause to resort to artificial means for producing them. In the case of a cherry or of a plum, each bud will contain both blossom and leares. 'The only pruning necessary in this case is where one shoot becomes much longer than the other, and causes the tree to present an unsightly appearance. In these cir-

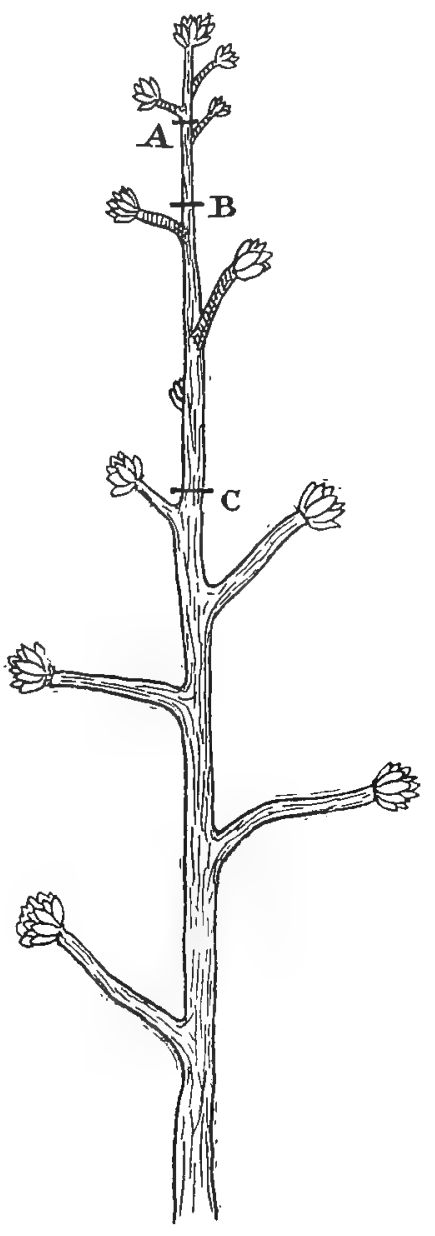

CHERRY AND PIJM (2).

cumstances the offending shoot can be pruned 
back to points $\mathrm{A}, \mathrm{B}$, or $\mathrm{C}$, and thus the tree may be kept evenly balanced.

Where bush or half-standard trees are grown, it is always best to aroid a crowded tree. The trees should be kept sufficiently thinned out, so as to admit the sun and air freely.

Apples and pears should be grown on the spur system. Cherries and plums are less adapted to the spur treatment, therefore it is best to grow them on the extension system, simply thinning out any shoots that may have the least tendency to crowd the trees.

'The directions given for the pruning of trees applies to trees in their dormant state only, and must not, in any way, be mixed up or associated with the "pinching of trees" in active growth, for which separate instructions are given in the following section.

Pinching of trees. - In olden times pinching was practised to excess, and it was no unusual thing to find a tree presenting the appearance of a hedge when clipped with shears. The result was a stunted tree with stunted fruit. Recently pinching has been done in a modified form, i.c. less severely, the result being the production of ornamental trees bearing fruit of good size and quality. With bush or half-standard trees, the first pinch is the essential one. The other pinching 
is intended to form a good and symmetrical tree. With pyramidal trees, however, a succession of pinching must necessarily take place, so as to keep the tree well balanced in its growth. With reference to the bush or half-standard tree, shoots $a$ must not be pinched at all, nor the small shoots in the intervals, as these must be allowed to grow, so as to succeed shoots a in the following year. None of the small spurs, i.e. the little shoots 2 or 3 ins. long, will require pinching, but the upright shoots will all require pinching, as follows :-

The following diagram is supposed to be a plan of a shoot 6 ins. long, ready for pinching, and this should be done byjust pinching out the point at mark $x$.

Some shoots will be much in advance of others, but as each shoot reaches the length of 6 ins. it should be pinched. As the shoots start again after the operation, when they have grown another 6 ins. they should be pinched again, and this may go on as often as necessary. The mistake sometimes made of allowing the shoots to grow on to the length of 9 or 10 ins. and then cutting them back 4 or 5 ins. should always be aroided, as this will excite the buds into growth, and fill the tree with laterals. If the instructions given be followed, few or no laterals will appear. 
58

\section{FRUIT TREES IN POTS [CH.}

Pyramidal trees should be pinched much in the same way, unless there are some shoots on one side of the tree which make strong growth, and

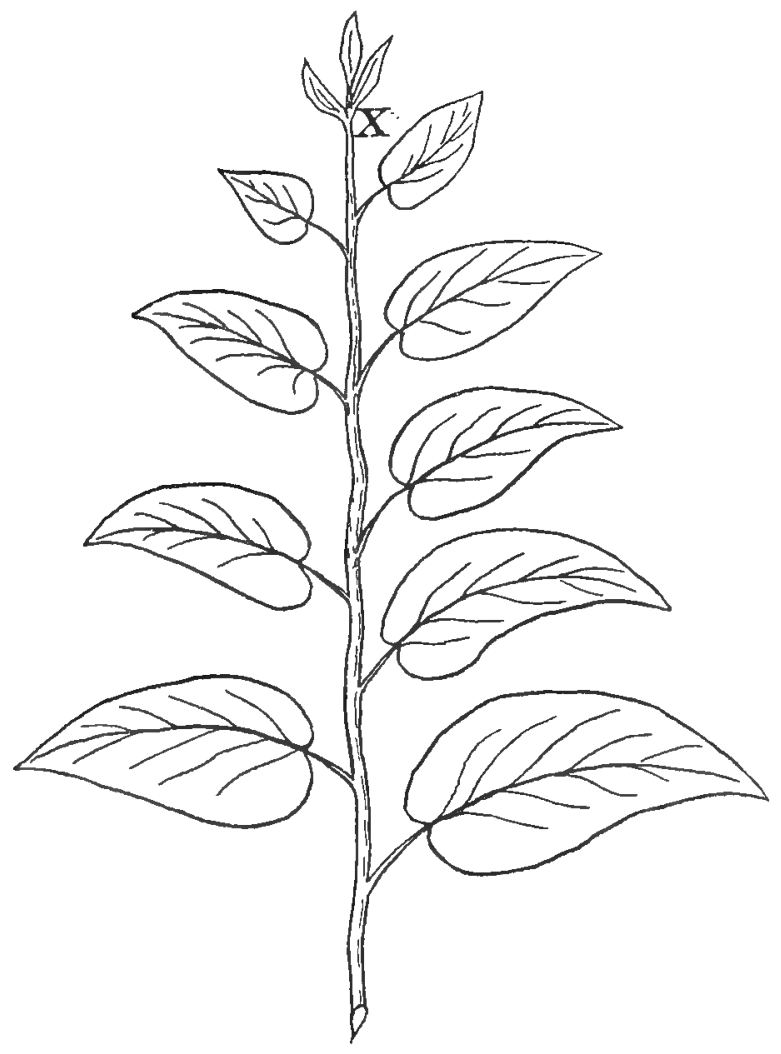

then these should be frequently pinched, the weaker shoots on the other side of the tree being allowed to grow on unchecked. The centre shoot 
of a pyramidal tree should be pinched after making a growth of 6 ins., so as to furnish the tree evenly with young shoots. This may be repeated two or three times, but not oftener, as the centre shoot should be allowed to grow on unchecked until the end of the season.

This operation may be practised on peaches, nectarines, cherries, plums, apples, and pears, wherever the trees are found to have made the extent of growth referred to.

It is also a good practice to pinch figs; and as some rarieties make a much stronger growth than others, it is best to vary the operation accordingly. 'The moderate growers should be pinched at 5 or 6 ins., and the stronger growers at 7 or 8 ins. The pinching of figs tends to harden the wood, and also induces the shoots to produce an abundance of fruit, which they probably would not do if allowed to grow at random.

Apricots may be pinched at every fourth or fifth inch of growth.

The growth of a pyramidal tree will always be found to commence at the top, and of course it must follow that the pinching must begin at the top of the tree, and not the bottom. It has recently been stated that the pinching of a pyramidal tree should always commence at the 
bottom; but this, in my opinion, is a grave error, and should never be practised.

There is another small matter which calls for a little advice, and this applies chiefly to the peach and the nectarine. These trees are generally worked on the plum stock, and in some cases the

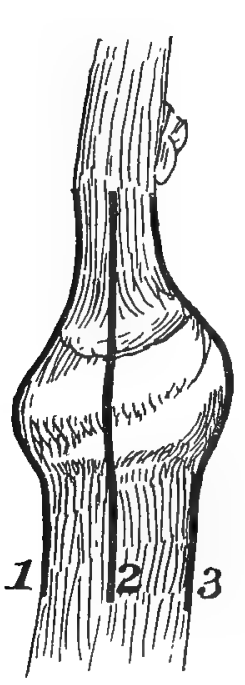
scion will grow more freely than the stock upon which it is budded. The result is the formation of a large collar at the junction-the stock becoming what is termed "hide-bound." 'The best remedy for this evil is to make three incisions with a sharp knife, taking care to cut right through the collar. The incisions should be of equal length both above and below the junction. They should be made one on each side, and the other in the centre, of the back of the junction, but not in the front (see illustration).

Nos. 1, 2, 3 represent the places where the incisions are to be made. 'The extent of the incisions should be about 2 ins. above and below junction. and $\frac{1}{8}$ in. in depth.

This will cause the bark to expand, and greatly assist in making fresh growth. 
The early part of February is the best time to perform the above operation.

Surface-dressing.--The best surface-dressing, to my knowledge, is that which is composed of "kiln-dust" and horse droppings. 'These should be mixed in equal proportions. Horse-droppings can generally be obtained, but it is not always so easy to secure kiln-dust, unless where there are "maltings." The term "kiln-dust" should be clearly understood, as this is not the common "malt-dust" which is obtained when malt is being screened, but the charred dust which comes from the malt-kilns as the malt is undergoing the drying process. Hence growers should be careful to ask for "kiln-dust." In mixing the compost, spread the kiln-dust and horse-droppings very thinly, say $\mathbf{2}$ or $\mathbf{3}$ ins. deep, and not more, and saturate it moderately well. If there is a " cesspool " containing any washings from the kitchen, such as soap-suds, it will answer well for the purpose. No strong liquid, such as urine and the like, should ever be used, but rather use clear water. Let the compost remain $2 *$ hours, and then turn it orer, and if it requires more saturating, it should be again done, and allowed to stand another $\mathbf{2 4}$ hours. It may then be used as directed in the calendar of operations for May. A second application may be made as the fruits commence 
to colour. This time a little more of the surfacedressing may be placed on the top of that which was first applied. The surface-dressing which was first applied should not be removed. This layer will probably be full of small fibrous roots, and if these are injured, the trees will suffer. It should be clearly understood that these surface roots above the rim of the pots should only be removed in the autumn, at the time of repotting.

Cherries and plums should not be surfacedressed when the fruits are rery small, but as these fruits commence stoning early, it will be prudent to defer the surface-dressing until their stones are formed, or partly formed. It is better to be a little late, rather than too early, in making the application.

Generally speaking, apples and pears may be surface-dressed by the first week in .June, if grown in a cool house, or if placed out-of-doors at the same time of the year.

The NuMBer of rRuts a TREe SHOULD BE ALLOWED TO CARRI AND RIPEN.-A grave error is often committed in the culture of fruit trees in pots, viz. that of over-cropping. It is no unusual thing to hear the remark, "I cannot understand the reason why I had such an abundant crop of fruit last year, and none this." Now, the grower should 
always bear in mind that a fruit tree has only a certain amount of strength, and if this strength is overtaxed, the tree will necessarily suffer

With regard to stone fruits generally, the fruit is produced on the young wood, i.e. on the wood formed the previous year, and if a tree is too heavily laden with fruits, it must follow that there will be but a small opportunity of its making young wood for the following year.

Some growers will have to cater for more.consumers than others, and under these circumstances it will simply be a question of quantity, not of quality. Every grower should adopt, as far as possible, the "happy medium," for by so doing he will gain the advantage of a crop of fruit each year.

The age of a tree is not always known to the purchaser, but as a good and safe guide to the inexperienced, the prices at which trees are generally supplied may here be quoted. Peaches and nectarines capable of bearing a good crop of fruit the first year are usually supplied in two sizes; the larger trees at $10 s$. $6 d$. per tree, and the second size at $\% s .6 d$. per tree.

If a peach or nectarine tree at $10 \mathrm{~s}$. $6 \mathrm{~d}$. is a large-fruited variety, it may safely carry 8 fruits; if a medium-sized rariety, $\mathbf{1 0}$ fruits; and if a small variety, 12 fruits. 
A tree costing $7 s .6 d$. may be allowed to carry a crop of fruit as follows :-

If a large-fruited variety, 5 or 6 fruits :

$$
\begin{array}{ll}
\text { ", medium-sized } & , \quad 8 \text { fruits ; } \\
\text {, small-sized } & 10 \text { fruits. }
\end{array}
$$

This table is intended to apply to the first year's crop only.

In each succeeding year the crop may be on an increasing scale, to the extent of 3,4 , or 6 extra fruits per tree, according to the size of the variety.

Apricots capable of bearing a crop of fruit are also supplied in two sizes, viz. at $7 s .6 d$. per tree and $5 s$. per tree. The larger-sized tree may be allowed to bear 10 or 12 fruits, and the smaller tree 6 or 8 fruits the first year, and an additional 6 or 4 fruits each following year.

Cherry trees seldom mature more fruits than they are capable of supporting, but some varieties bear heavier crops than others, and in the event of a tree carrying a large crop - and quality is preferred for exhibition, or any other special purpose - then the thinning of the fruits may take place. However, this should never be done until the stones are perfectly formed, as mentioned in the calendar of monthly operations.

Plum trees are also supplied in two sizes, viz. at $5 s$. or $3 s .6 d$. per tree.

Plums vary very much as regards fertility. 


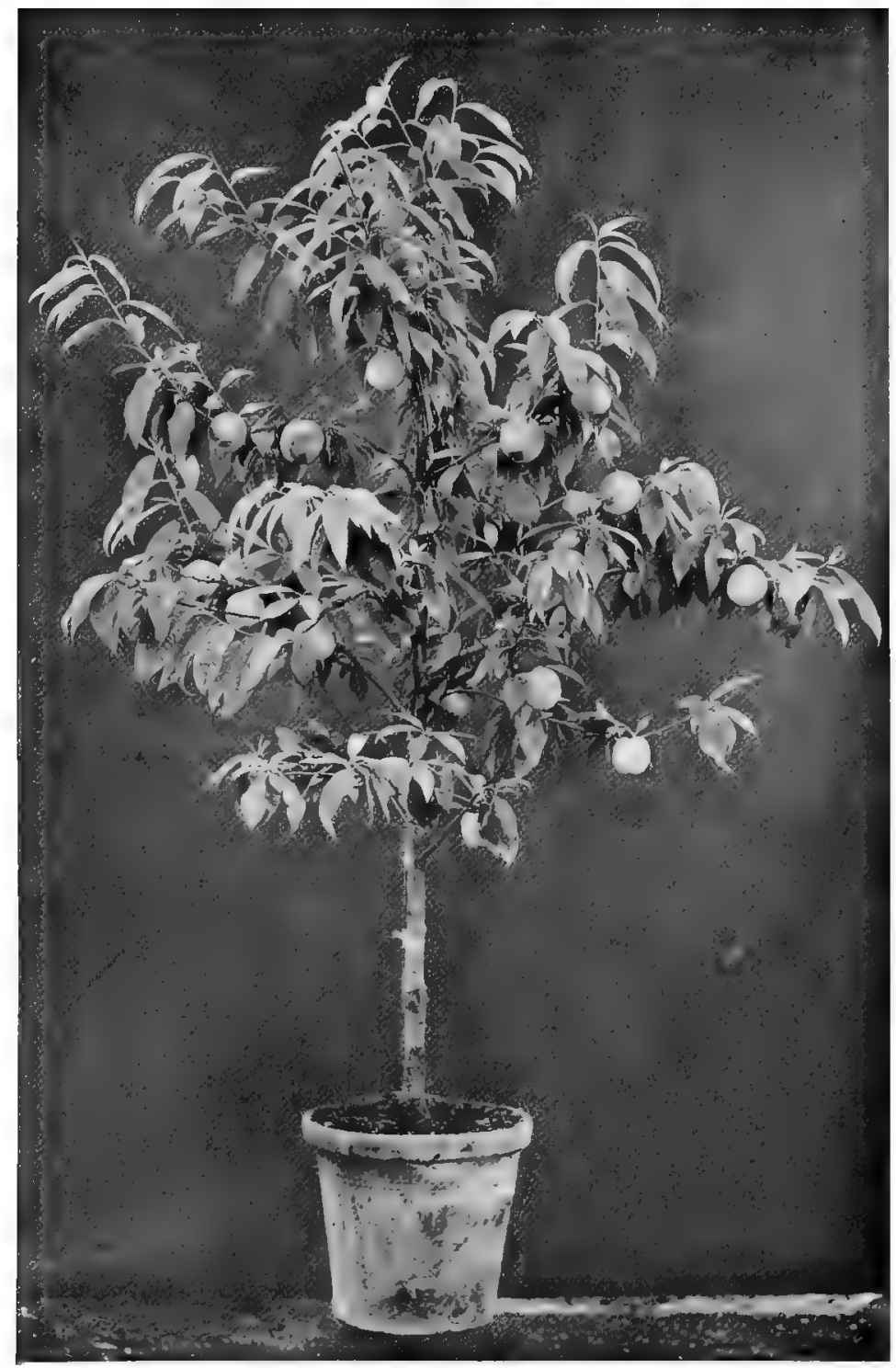

HALF STANDARD OF EARLY RIVERS PEACH.

[To farce p. 64. 

Some are abundant bearers, others are only moderate, and some are comparatively light bearers. These remarks are intended to apply to the abundant and moderate bearers only.

A tree costing $5 s$. may be allowed to carry a crop as follows:-

If a large plum, 30 fruits;

, medium , 36 to 40 fruits ;

, small , 48 to 50 fruits.

A tree costing only $3 s$. 6 . . should only bear a crop as follows :-

If a large plum, 20 fruits ;

, medium, 30 fruits ;

, small , 36 or 40 fruits.

As the trees increase in age and size, the crop may increase to the extent of 6,8 , or 12 fruits, according to variety.

The best class of apple and pear trees are those supplied at 5s. and 3s.6d. per tree, and as these fruits are closely allied to each other, the same table may safely apply to both.

A tree costing 5 . will safely carry the following :-

If a large variety, 8 fruits ;

" medium,, 10 or 12 fruits :

, small , 15 or 16 fruits.

A tree costing 3s. 6d. should only bear the following :- 


$$
\begin{aligned}
& \text { If a large variety, } 4 \text { or } 5 \text { fruits; } \\
& \text {, medium , } 6 \text { or } 8 \text { fruits; } \\
& \text {, small , } 10 \text { or } 12 \text { fruits. }
\end{aligned}
$$

Each succeeding year an increase of 3,5,6, or 8 fruits per tree, according to the size of the variety

In the foregoing table I have endeavoured to give a safe number for each tree to bear, but should any tree become sickly or delicate, it must be borne in mind that a light crop only should remain on the tree the following year. This will help to restore the tree to health and vigour, and what is lost one season will probably be regained in the next. It is somewhat difficult to determine what a tree shall bear and what it shall not bear, but if this table is followed with judgment, there will be little cause for regret. Of course, very many more fruits may be grown on trees in pots, but only at the expense of the quality of the fruit, and to the detriment of the trees as regards health and vigour.

Of course, there are both larger and smaller trees sometimes supplied by nurserymen; and if these are bought their capabilities may be easily arrived at, as they will either bear a larger or smaller crop according to the size of the trees.

Let no one imagine that the crop per tree 
recommended is a light one, for it certainly is not; but it is a perfectly safe crop, and if a careful study be made of the rate of increase per tree each year, the proof will be a convincing one, viz. that the trees will go on for many years, and there will be an increase in the crop annually.

'The longevity of FRUIT TREes IN POTS.The title of this section may appear somewhat paradoxical, but it is intended to show that fruit trees under cultivation will attain to a great age. I have frequently been questioned as to the length of time a tree would live in a pot. My reply has been that it would live to a great age, but the limit would be decided by the kind of tree grown, owing to some trees being more vigorous in their growth than others.

It has been my privilege to be brought in contact with fruit trees in pots as much as any person in the United Kingdom or elsewhere. Haring had trees entrusted to my care from a seedling in its earliest stages of infancy, to a peach tree which reached its jubilee, I am able to speak with authority.

Those who decide to grow fruit trees in pots may rest assured that it is not the short-lived thing of two or three years as some represent it to be. It is quite the contrary.

Peaches and nectarines will grow well and give 
good crops of fruit for 20 or 25 years, and even longer if required.

Cherries will also grow and give excellent crops for 30 years. I have seen some of the very finest examples of firuit produced on trees 20 years old and upwards.

A pricots pears, and apples will succeed equally well for 20 years.

Plums grow more freely than other trees, but their age may be fixed from 12 to 15 years. With proper treatment the ages given will in many cases be reached, if not exceeded. Personally, I am not a strong advocate for old trees (cherries excepted, and these I should always devote the greatest attention to, and not destroy them), but if a tree had done me good service for 15 or 20 years, 1 should always consider I had been amply repaid, and should have no hesitation in replacing it. Young trees can be purchased at a small cost, and if a few trees are bought every year, they will form an excellent reserve. They will serve to replace any old or shapeless trees. This will hare the effect of keeping a house fully furnished at a nominal cost.

Mulberries and figs will both live to a great age, with proper treatment.

In all cases the trees should receive an annual repotting or top-dressing as previously directed. 


\section{CHAP'TER IV}

\section{TARIETIES OF TRCITS}

Peaches and nectarines-Apricots-Plums-Cherries- $\Lambda$ pples and pears-Baking pears-'The mulberry-The fig-The vine.

Peacines and nectarines vary very much in constitution. Some rarieties succeed in a warm house, others do better in an unheated house.

'The American varieties of peaches, without exception, do not succeed when grown in heat and forced year after year. Their names are as follows :-Alexander, $\mathbf{W}$ aterloo, Amsden June, Hale's Early, Early Canada. 'These are all early varieties, and are often sought after for that reason. 'There are two kinds which will do fairly well if gently forced, and they are the Amsden June and Hale's Early. Although these American varieties do not succeed when forced, they all grow well and give good crops in a cool, i.e. unheated, house. 'The best varieties for late forcing are Sea Eagle, Princess of Wales, 'Thomas Rivers, and Barrington. If a yellow-fleshed peach is required, I strongly recommend the Golden Fagle. 
Both Barrington and Princess of Wales do well in a cool house.

The best early nectarine for forcing is the Cardinal, but this is only suitable for forcing, and not for a cool house.

The best late nectarine for forcing is the Victoria (but it does not succeed in a cool house). Early Rivers, Lord Napier, Stanwick-Elruge, Pine Apple, Rivers' Orange, Byron, and Humboldt, are all adapted for forcing. 'They also do well in a cool house.

'The white nectarine is much liked, but it does not force well.

Gathering the fruits. - With reference to the gathering of peaches and nectarines, a few hints may be acceptable. Peaches and nectarines have much shorter stalks than most other fruits, and often grow so near the shoot at the base of the fruit that they are easily injured if plucked from the tree in an ordinary manner. The best way to gather peaches and nectarines is to use a pair of grape scissors, haring fine points, and just cut the fruit away from the shoot. The fruit will not be in any way injured if this is carefully done.

Peaches and nectakines for cool houses. - There are other excellent varieties of peaches and nectarines which are well adapted for culture in a cool house. 'They are as follow: - 


\section{Peaches.}
Alexandr
Crimson
Dagmar.
Duke of York.
Dymond.
Early Alfred.
Early Silver.
English Galande.
Galande, or Bellegarde.
Grosse Mignonne.
Magdala.
Noblesse.
Royal George.
Stirling Castle.

\section{Nectarines.}
Advance.
Chaucer.
Darwin.
Goldoni.

Milton.

Newton.

Spenser.

Violette Hative.

Improved Downton.

Apricots must never be forced, but they can be grown in a cool house, and succeed better when grown in a house where pears and apples are grown, than when grown with peaches and nectarines. A little chalk should always be added to the soil, for apricots are very partial to a calcareous soil. A little night air might always be given, unless the weather be frosty. The leading varieties are given below in order of merit :-

Peach, or Grosse Pêche. Oullin's Early Peach. Royal. Hemskerk.

Early Moor Park. St. Ambroise. 
Pluass. - All the leading dessert plums are suitable for pot culture, especially the "gages," and the three best are Early 'Transparent, Golden Transparent, and Late Transparent. There are also some excellent kitchen plums which are well adapted for pot culture. Their names are as follows :-

Victoria.

Belle de Lourain.

Pond's Seedling.

Yellow Magnum Bonum.

White Magnum Bonum.
Early Rivers.

Late Prolific.

President.

Primate.

Cherries are an excellent fruit, and will hang on the trees for a long time after the fruit is ripe. 'There are various stages when the cherries benefit by some kind of shading. 'The best kind of shading is a roller blind of thin material, similar to that which is generally used for greenhouses. 'The advantage of this is that it can be let down or rolled up at option, whereas, if whiting, flour, or similar shading is used, it must remain on the glass whether the weather is sunny or dull. This will probably cause the fruit to be wanting in colour and flavour. The first stage where I would recommend shading is when the fruit is setting and the weather is very bright and warm; secondly, when the fruit is stoning; thirdly, when the fruit 


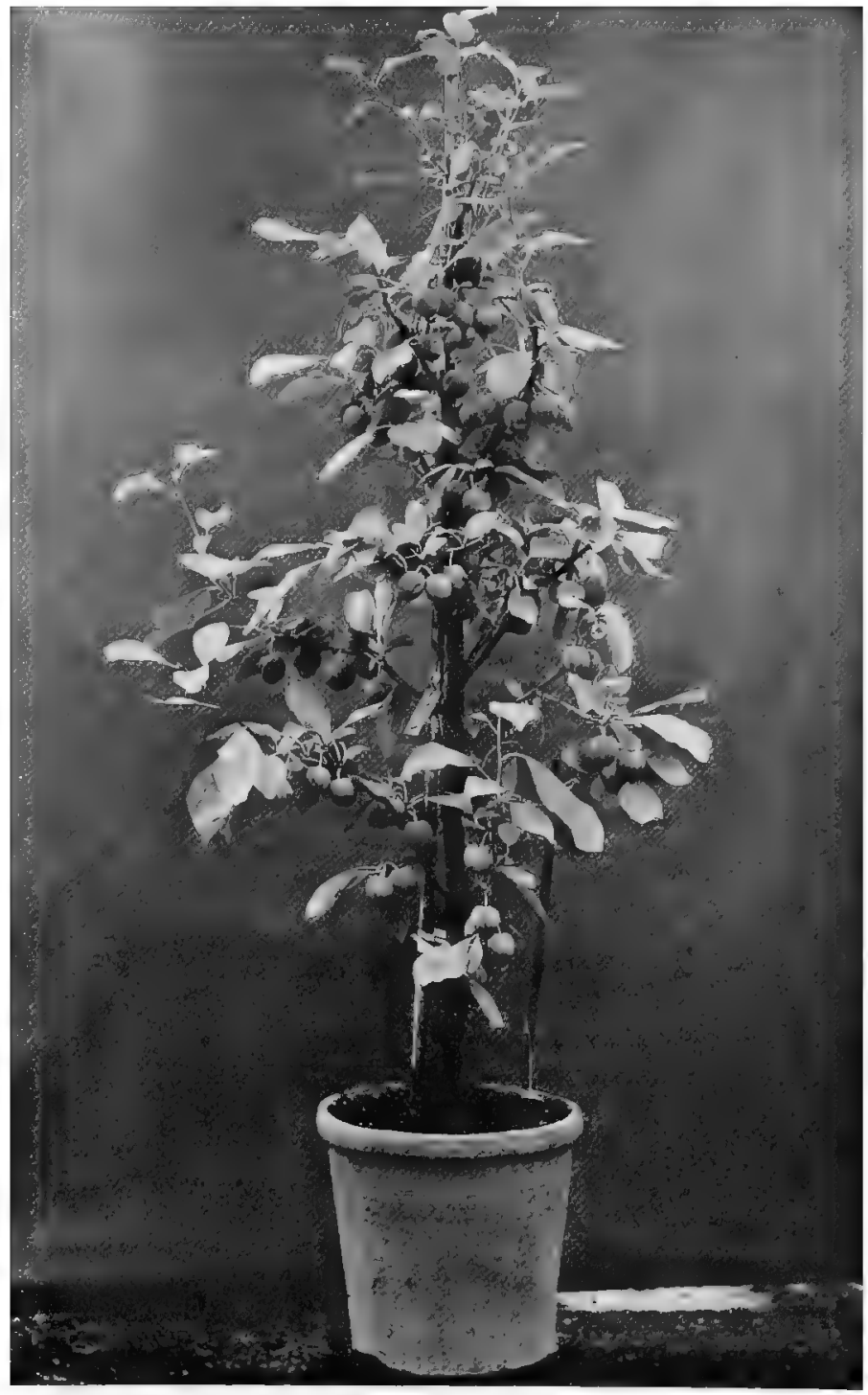

PYRAMID OF BLUE ROCK PLUM. 

is ripe, and it is required to be kept on the trees for some time. I have no hesitation in saying there are some varieties which can be kept in excellent condition for the space of one month. 'The best keeping cherry is the Early Rivers. Cherries, generally speaking, are not adapted for forcing, but the best kind for that purpose is the May Duke, and some people have been fairly successful with the Early Rivers, Elton, Frogmore, Bigarreau, Guigne Annonay, and a few other kinds.

All the best dessert cherries (and these are the Bigarreaus and Hearts), especially the black varieties, can be grown with excellent results in a cool house. Undoubtedly the Early Rivers' cherry is the cherry par eacellence.

Apples AND PEARs.-C The best dessert apples and pears are all worthy of pot culture, and for an ideal apple and pear the preference must be given to Cox's Orange Pippin apple and to Doyenné du Comice pear respectively.

There are also some excellent rarieties of kitchen apples which are worthy of a place in any collection, and are well worth growing, being large, beautiful, and useful. Where fruits are grown for exhibition purposes, they should certainly be included. Their names are as follows :-

The Queen.

Blenheim Orange.
Emperor Alexander.

Cox's Pomona. 
Bismark.

Gascoigne's Scarlet. Peasgood's Nonsuch.
Lady Henniker.

Newton Wonder.

Gloria Mundi.

'There are only two baking pears which I consider worth growing in pots, riz.-

\section{Catillac. \\ Vicar of Winkfield.}

'The MULberry.- The mulberry is an old and farourite tree. It is often grown for a twofold purpose. First, it is grown for its fruit, which is much sought after by some people; secondly, for its leaves, which are greatly in demand by those who happen to keep "silkworms," as these leaves form one of the best of foods for these useful and valuable creatures. It is no uncommon thing to find an old specimen mulberry tree growing on a lawn, or occupying a prominent position in many private gardens. It is not generally known that mulberry trees can also be grown in pots with excellent results. Their culture is identical with that of other fruit trees grown in pots in a cool house. They do not succeed when forced or grown in a house where artificial heat is used. With regard to pruning, they will require but little; in fact, the only thing necessary is to keep the tree evenly balanced-nature will do the rest. Pinching, too, being quite unnecessary, can be 
entirely dispensed with. It must not be thought that a mulberry tree in a pot is but a toy, and short-lived at its best. Such is not the case. I happen to know a very fine old tree which has been cultirated in a pot for upwards of 30 years. 'This tree continues to give an abundant and magnificent crop every year, with fruit of excellent quality. 'This old mulberry is still full of vigour, and as healthy in appearance as it was 15 years ago.

The nulberry, like other trees, when grown in pots, will be restricted in its growth. In these circumstances it would not be prudent to mutilate the tree by depriving it of its leaves for silkworms, as previously mentioned. 'The fruit will hang on the trees, if required, until the autumn, therefore it should not be removed from the house, unless from one house to another. Eren in this case, it should be given a position where there is plenty of light, sun, and air, but no artificial heat, as this would be detrimental to the crop of fruit in the following year.

Syringing should be discontinued as soon as the fruits commence to ripen.

The lig in heated and in crheated houses. - The fig is one of the best of fruit trees for pot culture. The trees grow freely, and give abundant crops of fruit, especially where artificial heat is 
used, and the proper varieties are grown. It must not be imagined that all varieties are equally good for forcing, but most of the largest and best sorts in cultiration are suitable for that purpose. They are as follows :-

Brown 'I'urkey.

Early Violet.

White Marseilles.

Black Marseilles.
Negro Largo.

Brown Ischia.

Violet Sepor.

Pingo de Mel.

Of course there are other good kinds which are also adapted for forcing, but the above are reliable kinds which can be safely recommended. The culture of figs is not always attended with the success one might wish for, but this often originates from their being grown under unfarourable conditions.

The fig, in the first place, has a tendency to strong growth. It is also a gross feeder. So some cultivators insist upon using a strong and very rich soil, and in addition to this, they prune the trees too severely.

These are grave errors, as they only tend to cause the production of a very strong and sappy growth, and the result is little or no fruit.

Overcrowding, and growing the trees in too shady a position, should also be aroided.

For the successful culture of figs in pots I 
should adrise the use of a fairly good soil. I know nothing better than that recommended for peaches and nectarines.

'The same kind of surface-dressing would answer admirably. It is always best to supply them with food in this way, as fig trees form an abundance of surface roots. 'The use of strong liquid or artificial manures is not to be recommended, as both help to encourage a strong and unfruitful growth. Pruning should be performed with discretion, i.e. moderately, and not severely in any case. If a rery strong shoot appears, it is best to cut it right away rather than prune it to two or three eyes.

Pinching tends to harden the wood, thus making the tree more prolific.

Figs-especially the hardiest rarieties-can also be grown in a cool house with good results. The best fig for growing in a cool house is the Brown 'I'urkey. There are also other kinds, such as the Brunswick, etc., while, as has been said, nearly all the varieties force well.

THE vINE.-If vines are grown in ordinary pots, they must be grown on the alternate system, viz. by allowing the plants to do one year's work, and then to have one year's rest. By this, I mean it would be necessary to renew the soil after a year's hard work, and this would disturb the roots of the vine, and so injure the fruiting for the next 
year. Now, vines can be grown in the perforated pots already mentioned for a good number of years, even in a limited space, and give good crops annually. The only thing necessary is to follow the instructions already given.

It is no unusual thing to find people who are quite unacquainted with the rarieties of fruits. This places them in a difficulty when making a selection. Such persons should place themselves in the hands of a reliable firm, and allow them to select trees for them. They will seldom, if ever, regret such a step. They will also gain other advantages, as they will receive a selection which will ripen in succession, and which will include the best varieties. 


\section{CHAPTER V}

\section{INSECT AND OTHER PESTS}

Green fly-Brown aphis-Red spider-Thrip-Earwigs-WeevilsAnts-Mildew, etc.

There are many kinds of insects which attack fruit trees, especially "stone fruits," and cause them to present a sickly appearance.

GreEN FuY.-This is easily detected, for it causes the leares to curl up. It also attacks the fruit, and causes it to become deformed, if no step is taken to destroy the insect. The best remedy is to fumigate or use an insecticide. 'This fly is the first to attack the trees.

Brown aAd BLACK APHIDEs. - These are the next enemies, and require the same treatment.

RED SPIDER.-If the weather is warm, and syringing or damping of the trees or borders is neglected, these pests soon obtrude themselves. 'This is a small insect, and is to be found on the back of leaves, chiefly near the rib of the leaf. This insect is soon discovered, for it will cause 
the leaf to present a yellow or spotted appearance. Whenever the fruit is not ripe or ripening, the most simple remedy is a good syringing with rainwater. If unable to apply the syringe, then use a little insecticide or quassia, applying it with a small painter's brush.

'THRIP.- Thrip is an insect (brown or black) very much resembling what is commonly termed "thunder bug." It often causes the leaves to partially curl up, and gives them a white or silverlike appearance. The same remedy should be used for thrip as for red spider.

EARWIGs.-These insects often put in an appearance when the fruit is ripening, and generally attack nectarines more than peaches. Their presence will soon be detected, for they will puncture the crowns or apex of the fruits, and so cause them to decay. There are two very simple but very good traps in which to catch these intruders. First, some pieces of soft newspaper can be folded up and placed round the stems and on the lower branches of the trees. The earwigs will crawl into the folds of the paper, and can be shaken out and easily destroyed. Secondly, some beanstalks can be placed on top of the pots and also about the tree, and the earwigs will crawl into these hollow stems, and can be shaken out and destroyed. 


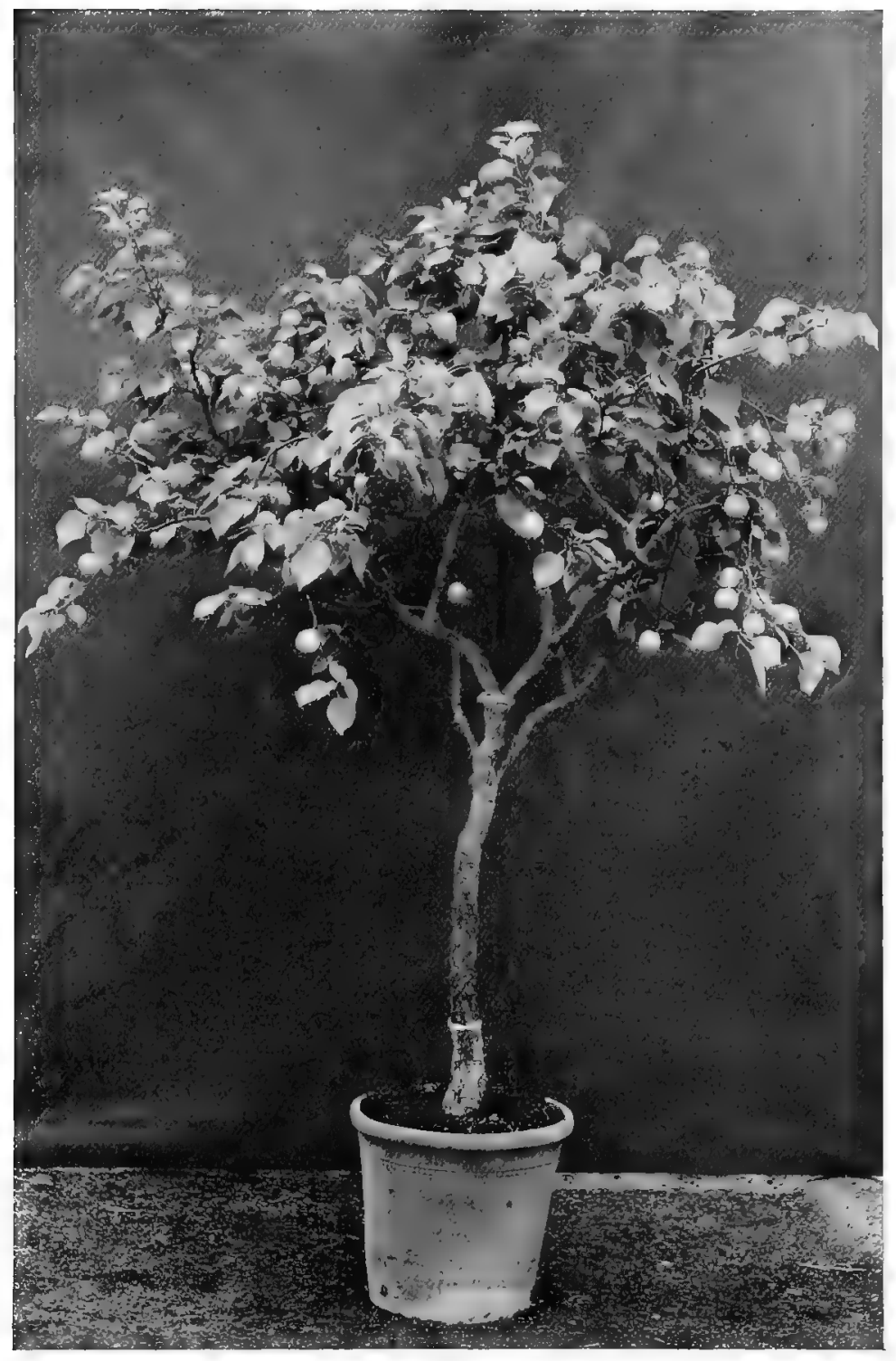

HALF STANDARD OF PEACH APRICOT.

[To face p. 80. 

Peach weevil.-This is a small beetle, which attacks the fruit much after the manner of the earwig-at night only. Hence night is the only time when it may be caught.

Apricots, apples, cherries, plums, and pear's are all liable to be infested with a small grub during the first stages of growth. This grub is easily detected, as it generally shows itself in the young and tender leaves, and hides itself between two leaves or curls up in one leaf. It is also found in the flowers sometimes. There is but one effectual way of destroying this insect, viz. by picking them from the leaves or flowers and killing them.

Ants are very annoying and destructive insects, and should be closely watched. When fruit trees are in flower the ants will secrete themselves in the centre of the flowers and eat away a large number of stamens, thus depriving the flowers of the pollen which nature provides for fertilization; and again, when the fruit is ripe, the ants will eat much of it if allowed to go on unchecked. 'The remedy against ants is as follows: Get a piece of soft chalk, or whiting, and rub it on the stems of the trees, making a ring all round the stems (and also the stake, should one be affixed to the tree) to the depth of 2 or 3 ins. As long as this remains dry the ants will be quite unable to pass 
over it, owing to its being too slippery. In the event of the chalk becoming damp and sticky, the ant will easily pass over it. Watch this carefully, and renew the application whenever necessary.

Misdew.-C'This will sometimes show itself on peaches and nectarines, and I know of no remedy other than a little powdered sulphur, which should be dredged or sprinkled on the affected parts. Prevention is far better than cure, and if strict attention be given to instructions in the calendar with regard to syringing at night, no mildew will appear.

'The leaves of fruit trees in pots sometimes become yellow and sickly. This may originate from over-watering, or the absence of iron in the soil. The remedy for this is a rery simple one. Procure a little sulphate of iron from a chemist, and thoroughly dissolve $\frac{1}{2} \mathrm{oz}$. in 1 gallon of water, and water the affected trees once or twice a week with solution until the foliage improves and regains colour.

Geverai, mints. - Unless well rersed in chemistry, it is better never to use chemicals in water when watering trees. To destroy aphides do not use any strong insecticides. One of the best and safest is an infusion of quassia. This can be obtained from any chemist or horticultural 
sundriesman. Use it in the following proportions: 'To 1 gallon of cold rain-water add 4 ozs. of quassia chips, and allow the chips to remain in the water for 36 or 48 hours; then strain the liquid from the chips, and in the liquid dissolve 2 ozs. of "soft soap." This liquid may be applied to the affected parts of the trees with a small painter's brush.

Another excellent remedy is the XL All liquid insecticide. 'The more effectual way of eradicating insects of all kinds is by using the XI. All fumigator.

I would always recommend a good winter dressing, by well brushing the old wood and stems with quassia or the XLAll insecticide for peaches, nectarines, apricots, and cherries. Care should be taken to dress the old wood only. It would be very risky to dress any of the young shoots of the last year's growth, as many of the fruit buds would probably be much injured.

'The remedy to be applied for the destruction of any insects on the young wood of the abovementioned trees, and also for plums, is a fumigating in their dormant stage. This should take place just before any of the blossom buds commence to open. I would never advise the use of "tobacco paper," as it is next to worthless, and does more harm than good; but I strongly 
recommend the use of the $\mathrm{XL}$ All, or something equally good.

It must not be thought that every tree will become a victim to each and every one of these pests, but every one should be on his guard, so as to be ready for battle, should the enemy appear. To be forewarned is to be forearmed; and should the enemies appear on the scene, commence firing.

Fumigating. - Whenever it is necessary to fumigate a house, a quiet night should be selected if possible. The trees should not be syringed the day on which the fumigating is to be done, and the damping of the borders and paths should also be withheld.

Of course, the trees may be watered, should they require it, but even this ought to be done as early in the day as possible.

The fumigating should always take place in the evening. About 5.15 or $\mathbf{5 . 3 0}$ is a good time to commence, unless the weather is very sunny. and then it might be deferred half an hour. The morning following, the trees should be well syringed, but not too hearily if only in the first stages of growth.

The syringing will hare the effect of cleansing' the trees from the dead insects. 


\section{CHAP'TER VI}

A CAIENDAR OF OPFRATIONS IN THE UNHEATED HOUSE FOR EACH MONTH OF THE YEAR

JANUARY.- The trees at this season will be in their winter quarters, with the pots covered. The only thing necessary is to open the rentilators whenever weather permits. This remark is intended to apply to mild, or fairly mild weather, in fact, when it is not freezing.

Do not fail to admit plenty of air into the house the whole of the day, but close the rentilators during the night, unless it be extremely mild weather, and then a little night air will help to retard the trees.

About the middle of this month, if there is no frost, choose a nice mild day and remove covering material from the top of the pots only, and give all trees some water once only, as this will be sufficient till the following month. Should there be a reappearance of frost, recover the top of each pot at once.

Febrtary.--Tentilate freely whenever the 
weather is suitable and there is no frost. Give one more watering during the first week of this month. The pruning of the trees should be done from the middle to the end of this month, and another watering should be given (see pruning instructions, p. 43).

March.- The trees should now be arranged in the house, and placed in proper positions for the growing season. Water the trees once a week, and rentilate freely all day, but close at night. It will be necessary to watch the weather this month, and in the event of the occurrence of frost, care must be taken to protect the blossoms. 'The trees will probably be in flower some time this month. 'They may be protected by the use of hot-water pipes, etc. 'There will be no necessity for a high temperature during the flowering stage, as this would be more injurious than beneficial. 'The idea is simply to protect the trees when in flower. This can be done safely by keeping the temperature of the house from $38^{\circ}$ to $40^{\circ}$ Fahr. AT Night.

Where the house is of good size, I would strongly recommend the addition of a suitable boiler, and a 4 -in. hot-water pipe running round the house-simply one pipe on each side-to be used only during the time the trees are in flower. This will only be about three weeks or a month. The flow-pipe should always be on the north side of 
the house. In small houses, hot-water pipes are notan absolute necessity, as there are various other means of supplying the required heat. Paraffin lamps, or stoves, may be used with ad rantage, but, where used, every care should be taken to ensure the wicks not being so high as to emit noxious fumes, which would be injurious, if not fatal, to the flowers of the fruit trees.

Fire, or artificial heat, in the ordinary course. will only be needed at night. I'nless there is severe frost during the day, do not use any artificial heat, as the sun will supply all that is required.

Is the trees come into flower it will be necessary to watch the fertilization of the flowers. Bees are undoubtedly the best fertilizers, and if a good number visit the flowers daily, there will be no need to resort to artificial means. Should the weather be unfarourable for bees to leare their hives, then artificial means should be adopted. 'The flowers should be brushed daily, as lightly as possible, with either a hare or rabbit's tail, or, which may answer better, a small camel's-hair brush. The operation is a simple one. Just gather the pollen from the small-flowered peaches or nectarines and convey it to the large-flowered rarieties. When the brush is full of pollen, take all the trees in rotation.

Ventilate the house early in the morning, and 
do not close till late in the afternoon, say from 5 to 5.30 , if the weather is warm. Always give a current of air if possible when trees are in flower. In the event of strong winds, open the rentilators on the opposite side to the wind, as far as is safe, and give a small amount only on the windy side, so as to aroid any stagnant air. But in warm and quiet weather open all ventilators as far as possible during the flowering stage.

I have mentioned March as the month in which the trees come into flower, but of course seasons vary. In some years the trees will probably flower earlier than others, but if the foregoing instructions are observed, they will apply to the flowering stage whenerer it may be.

Where apples, pears, or plums have been wintered out-of-doors, they should be carefully watched towards the end of this month, or during the early part of April. 'They should be placed indoors just before they come into flower, so as to protect them from frost.

A PRI.. - The fruit will now be setting, or some of it set by this time, and great care should be taken not to increase the temperature too rapidly. A temperature ranging from $45^{\circ}$ to $50^{\circ}$, or $55^{\circ}$ to $60^{\circ}$, with ventilation, will be the best during this stage.

I am perfectly aware that on some days, if it 
is bright and sunny, the temperature will rise much higher than even $60^{\circ}$, but the only thing necessary is to ventilate freely, to keep the temperature as near as possible to the temperature specified.

Watch the growth of trees, as insects often appear, especially green fly, during the early stage of growth.

'The best way to destroy them is by fumigation, and the best and safest remedy is the XL All fumigator. This can be supplied by Mr. G. H. Richards, 234, Borough High Street, London, S.E., or through any horticultural sundriesman.

It will probably be necessary to make the first thinning of the fruits during this month. It is best to do this with discretion, and not to be too severe at first, so my advice is, simply single out the fruits.

With reference to watering during this month, give sufficient water as often as the trees require it. This will easily be ascertained by giving the pots a gentle tap; if the trees are dry, the pots will give forth a hollow or bell-like sound.

Do not follow any fixed rule for giving water, i.e. so much per day, or two days, as this is a bad practice. Give water when it is needed, and then only. If the trees are putting forth young growth (which they probably will be), give a slight and 
gentle syringing each morning. This will assist both trees and fruit in developing.

$M_{A Y}$. W Watch the growth of trees, and if any of the shoots require pinching, see that this is done.

'The watering should be well attended to, for at this season of the year it will be quite safe to give a liberal supply when necessary. The same rule will applyas mentioned in the previous month, only it will be adrisable to watch the soil around the rims of the pots. Should the soil be found to be parting from the pots, fill up the space at once, using either the hook used for potting, or a pointed stick, for the purpose. This is an important matter, for if the soil is allowed to part from the rim of the pot, the water will find a quick outlet through the space, and so the ball of soil will receive little or no water, and the result may be serious.

This should be observed until the trees are surface-dressed.

Let the watering be done in the morning, or not later than midday, and syringe in the morning only. A slight sprinkle should be given to the borders and paths of the house when closing in the evening.

A further thinning of the fruit will be needed, so remove all deformed and some of the smallest 
fruits, but do not thin too severely. It is a good practice to take off a few fruits weekly. Of course, thinning of fruits only applies to cases where there is an abundance, for if there is a light, or very small crop, no thinning will be necessary. Too many should not be taken off at once. The final thinning should not take place until after the stoning. The best way to know when the stones are formed is to cut a few fruits, and if the stones are quite hard, then they are all right, and the final thinning should take place.

The first surface-dressing may be applied when the fruits hare attained the size of a small walnut, but not before.

None of the soil from the pots should be removed, but place the compost, whatever it may be, on the top of the soil so that it comes about two inches abore the rims of the pots. Leare a small hollow, or bowl-shaped space round the stem of each tree, as this makes the best receptacle for the water.

Watch the weather during this month, and give ventilation early in the morning, when warm, allowing the temperature to range from $60^{\circ}$ to $70^{\circ}$. Should it exceed this, ventilate freely, and close house at night.

JunE.-Place out-of-doors all apples, pears, and plums that are not required to ripen their 
fruit under glass. The best site for them is a sheltered position with a south or south-west aspect.

Each tree should have a stake affixed to it, as a protection against wind, etc. It is always best to plunge the pots to about three-fourths of their depths, or even up to their rims, placing some rough cinder ashes at the bottom of each hole for the pot to rest upon. By so doing the tree will be prevented from becoming water-logged. Apples, pears and plums, with the exception of the late varieties, will ripen very well out-of-doors. But in autumn it will be wise to place the late kinds under glass again, as the adrantage will be twofold. First, the fruit will be protected from the strong winds often prevalent during the month of October; secondly, the fruit will hang much longer on the trees, thus making their culture far more interesting.

In the event of apples, pears, and plums haring been grown in the same house as peaches and nectarines, the vacancies caused by their remoral should be used for the peaches and nectarines, as they will succeed better if extra space is given them.

Syringe peaches and nectarines every morning between the hours of six and eight o'clock, unless the weather be wet and cold. Also give rentilation before eight o'clock, weather permitting. 


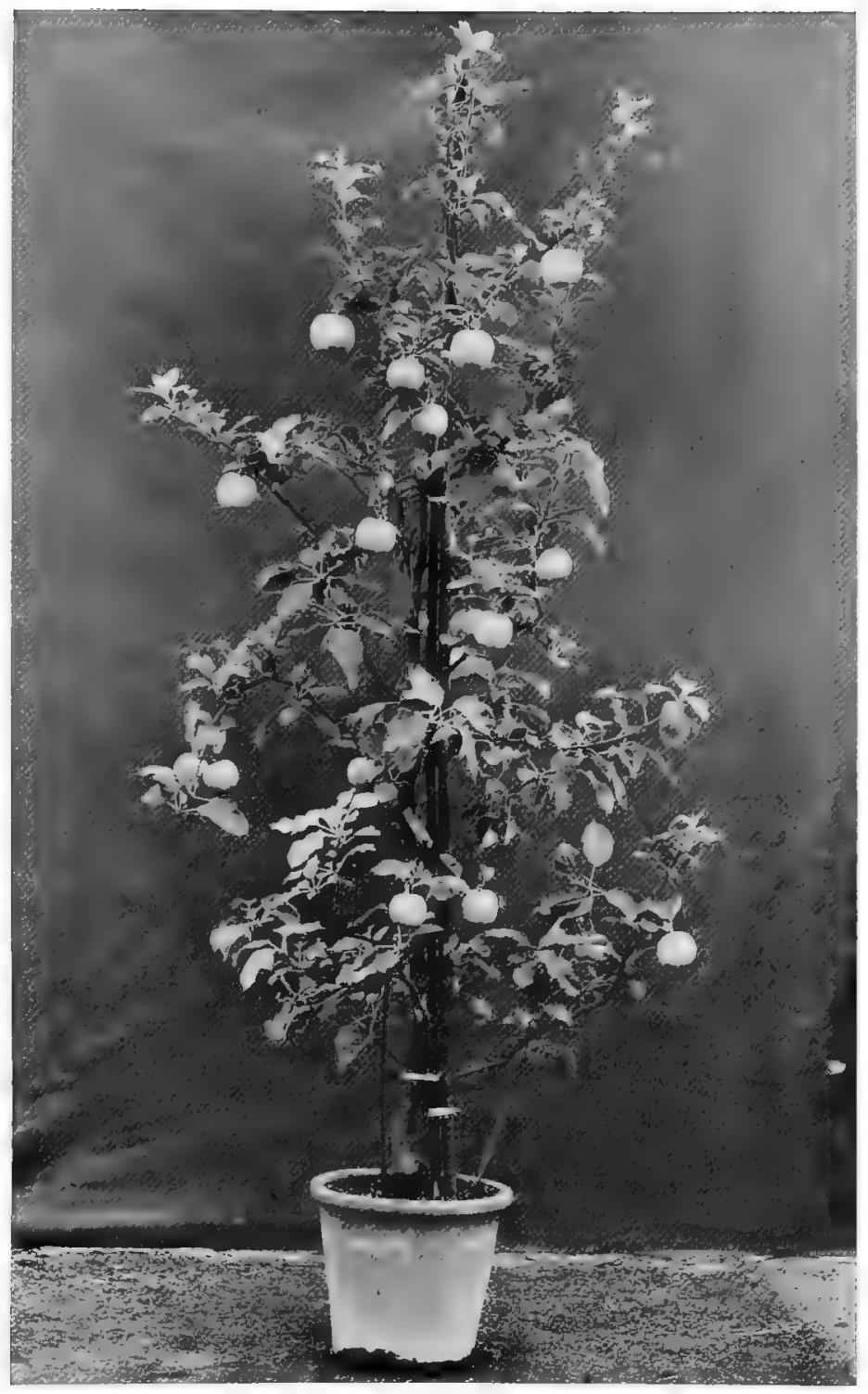

PYRAMID OF KING OF TOMPKINS COUNTY APPLE.

[To face p. 92 . 

Assuming the weather to be warm and seasonable, syringing may be done each night as well as in the morning.

Although reference has been made in the previous month to the final thinning of peaches and nectarines, it does not follow that thinning will always take place at the same time. Some seasons are much later than others. The final thinning must always be regulated by the season.

An occasional watering with liquid manure may now be given, say once a week, but choose a bright day if possible for the purpose.

The best liquid manures to my knowledge are, good stable manure, containing plenty of horse-droppings, or stable manure and cow-dung; but of the two I should give preference to the first.

A bag of soot tied somewhat loosely, but securely, should be placed in the liquid, and be well shaken before the liquid is used. By so doing the good properties of the soot will mix with the liquid, and help the foliage considerably. Commence by using 50 per cent. of the liquid ; later on, increase to 75 per cent. (in each case the remainder should be clear water), and as the season goes on the liquid may be used alone, if not too strong. The best way to find this out is to water one or two trees only each time, and watch the results. 
Never use any urine, or clear liquid from a stable, as the result would be fatal.

Jur. - The earliest varieties of peaches will in all probability be ripening now, and care should be taken not to syringe the ripe, or nearly ripe, fruits, as the water would damage them very much.

It is a good plan to place all the early varieties together in one part of the house. This can be done either as they ripen, or when arranging the trees in the early part of the season.

As a remedy against red-spider, etc., keep the border underneath the ripe fruit well sprinkled, instead of syringing. This treatment will apply to all rarieties as they ripen.

Nectarines ripen a little later than peaches, but it will be necessary to treat them in the same manner during the ripening period.

After the fruit is gathered from the early kinds, and also some of the mid-season rarieties, the trees may be placed out-of-doors, in a position with plenty of light, and a south or as warm an aspect as possible. The trees should be plunged in the ground to the depth of two-thirds of the pots. A little rough cinder ash should be placed at the bottom of each hole when plunging, as this will assist drainage, and prevent the ingress of worms.

The trees should be watered whenerer dry 
just as though they were in the house, for it must be borne in mind that the foundation has to be laid for the next crop of fruit.

The placing of some of the trees out-of-doors has the two following adrantages:-

First.-Additional space will be given to the trees remaining in the house.

Secondly.-The trees out-of-doors will have the benefit of extra light and air, which will assist in ripening the wood and maturing the fruit buds. Let the house be freely ventilated during the day, and during warm weather give some night air also. This will add to the colour and flavour of the fruit; in fact, it is a good plan to commence giving a little night air as soon as the fruit begins to colour. This remark should always apply to cherries and plums.

$W$ atch the watering carefully, and give sufficient water to each tree when dry. 'This may sometimes be two or three times daily. In each case the water given should be sufficient to pass through the ball of soil, and run out at the bottom of the pot freely.

AugusT.-During this month a large number of both peaches and nectarines will ripen their fruits. After the fruit has been gathered; it is not requisite that all trees be placed out-of-doors. Such is not the case, unless the house is wanted 
for some other purpose, for a period not extending orer eight or ten weeks.

As a safe guide, if one-third of the trees be removed from the house, there will be ample space for the remaining two-thirds.

The late and unripe varieties should be syringed both morning and evening until they commence to ripen. All trees from which the fruit has been gathered should also be syringed in the same manner.

Attend to the watering, and give a liberal supply to all trees both in and out-of-doors.

Let the house be freely rentilated botl day and night.

September.-The fruit will now have been gathered from a good many trees, and to these the syringe should be liberally applied both morning and erening, as mentioned in August. By so doing the fruit buds will be greatly assisted in their derelopment, and red-spider, etc., will also be kept at bay.

Let the trees be watered whenerer dry, and let the house be rentilated as much as possible both day and night, exercising constant vigilance, so that in the event of early autumn gales, too much ventilation may not be given on the windy side of the house ; and let the rentilators be closed at night. 'This remark only applies to windy 
weather. Towards the end of the month--.or very early in October-the soil for potting should be prepared.

OctoBEr. - The potting should be done during this month, and it is always best to commence with the most advanced trees. 'These will be the trees which have been placed out-of-doors. Let plenty of ventilation be afforded, as this will help to ripen the wood thoroughly. Wrater the trees once or twice a week during this month.

Novfander. - The potting of trees will probably have been done by this time, but if any have not yet been potted, every effort should be made to complete that operation.

It will be desirable to arrange trees in their winter quarters after they are potted. 'The best method is to place them in single rows, as this will economize space. The best way of doing this is to place two of the tallest trees just far enough apart to admit a short one between them. The leares should not be remored from the trees by pulling or cutting them off, as this is a bad and unwise practice. Use the syringe every morning (unless frosty), and this practicewill suffice both as regards helping the leaves to fall, and also in assisting the development of the blossom buds.

Should no frost appear, the newly potted trees, whether potted or top-dressed, should have 
an occasional watering if the soil is dry, but the watering should be discontinued after the third week of this month.

Watch the weather, and have covering materials in readiness, should severe frost set in. Let the house be freely rentilated from morning till night, unless frosty.

December.- The best materials for corering trees are barley straw or meadow hay, but, of the two, the former is the best. Cinder ash is sometimes used as a covering, i.e. the trees are massed together, and then the ashes are thrown against the pots, and also on top of the pots, to the extent of 2 or 3 or even 6 ins. above the rims; but I should never advise the use of ashes if either of the abore-mentioned materials can be obtained. 'The covering of the trees during frosty weather should be performed in the following manner: Cover the pots to the extent of $1 \mathrm{ft}$. all round them, taking care to put plenty of the covering material between the spaces from pot to pot. Wedge this firmly in, to prevent frost passing through, and cover the tops of the pots to the extent of 9 ins. to $1 \mathrm{ft}$. This will be sufficient covering.

Oak leaves and beech leares form a good covering for trees out-of-doors in pots. All the hardy fruit are better wintered out-of-doors, if 
placed in a sheltered position and well protected, i.e. in the same manner as that recommended for trees in a house.

Apricots, peaches, nectarines, and cherries should always be placed in the house after they are potted, and never allowed to remain out-ofdoors during the late autumn or winter.

Let no water be given to any trees during this month, and let no artificial heat be applied, as this would advance the growth of the trees.

Whenever the weather is mild, and not frosty, let the house be freely ventilated. 


\section{CHAPTER VII}

\section{MISCELLANEOLS OBSERVATIONS}

Flavour-Gathering the fruit-Fruit trees for decorative purposesMiscellaneous directions, etc.

Gatherisa the frcit.-People have often astonished me by saying that fruit from pot trees is lacking in flavour. 'This depends very much upon the conditions of growth, and also the gathering of the fruits.

Reference has already been made to the conditions of the growth of trees, but no mention has been made as to the best time for gathering the fruits. 'This should take place some hours after the trees have been watered; $\bullet . g$. if the watering has been done in the morning, the fruit should be gathered in the afternoon, or vice cersa If the fruit can be gathered during sunshine, so much the better. Never allow the fruit to remain on the trees until it is over ripe; rather gather it a day or two earlier, and allow it to ripen off the tree.

If these instructions are followed, the flavour of the fruit will be greatly assisted and improred. 


\section{('H. VII] 'TABLE DECORA'TION 101}

Frite trees for decorative perposes.Fruit trees in pots are undoubtedly one of the most useful things for decorative purposes, especially for table decoration. For years it has been a matter of the greatest surprise to me that they are not more extensively grown for that purpose. Nothing can be more beautiful than a peach, nectarine, cherry, or plum tree growing in a pot, laden with beautiful and fine-coloured fruit. Surely such trees are wortly to grace any table? It would afford pleasure to the guests to gather the fruit from the trees instead of taking them from the dessert dishes.

The temporary transfer of the trees from the glasshouse to the dining-room would not injure them in the least. 'The day following they could be again returned to their former positions, none the worse for the little excursion save being denuded of their fruits.

Apples and pears, though less imposing, are equally adapted for decoration.

Miscelianeors directions.- Do not make a practice of putting all sorts of bedding and other plants in the house, and so converting it into a hospital for all sorts of patients; but make the right use of it by growing the proper trees in itand grow them well.

In the early part of the season, when the trees 
are arranged in the house, the introduction of a few double German wallflowers in pots, or a few bulbs such as hyacinths, tulips, and the like, may be permitted, as they would add to the beauty of the house, and help to attract the bees. Again, in autumn, if the pot trees are placed close together, a few chrysanthemuns might be grown in the vacant part of the house. But always remember never to sacrifice the pot trees for the sake of other plants or flowers.

Where reference is made to temperature it is intended to apply to the day temperature only. The night temperature in cool houses, of course, can be decided by one thing only, viz. the weather.

Always secure as much rain-water as possible, as this is inraluable for syringing.

Avoid using strong liquid manures, especially urine, and also strong artificial manures, such as guano, nitrate of soda, and the like.

Never keep a house closed when trees are in flower, but rentilate freely, whether the house be a cold louse or a forcing house. 'This should be strictly observed.

Vines and roses should never be grown with peaches, nectarines, and apricots, as they never succeed when grown together. 
A Supplementary Iaste of Dessert Apples, Pears, Plums, axd Cherries.

This list contains the choicest varieties of fruit for dessert, and those best adapted for pot culture, arranged as nearly as possible in the order of their ripening.

\section{-Apples.}

Mr. Gladstone.

Beauty of Bath.

Rivers' Early Peach.

Iady Sudeley.

Red Astrachan.

William's Farourite.

\section{Benoni.}

Devonshire Quarrenden.

Kerry Pippin.

Mother.

Washington.

Ribston Pippin.

Cox's Orange Pippin.

King of the Pippins.

Scarlet Golden Pippin.

Melon.

Mannington's Pearmain. 
King of 'Tompkin's County.

Reinette du Canada.

Buckingham.

\section{Pears.}

Jargonelle.

Clapp's Farourite.

Dr. Jules Guyot.

William's Bon Chrétien.

Beurre d'Amanlis.

Souvenir du Congrès.

Madame Treyve.

Marguerite Marillat.

Beurre Superfin.

Beurre Hardy.

Fondante d'Automne.

Louise Bonne of Jersey

'Thompson's.

Parrot.

Gansel's Bergamot.

Conseiller de la Cour.

Marie Louise.

Conference.

Magnate.

Pitmaston Duchess.

Doyennè du Comice.

I) urondeau. 
Marie Louise d'Uccle.

Duchesse d'Angoulême.

Princess.

Beurre Diel.

Beurre Bachelier.

Beurre d'Anjou.

$W$ inter Nelis.

Josephine de Malines.

Nouvelle Fulvie.

Olivier de Serres.

\section{Plums.}

The Czar.

Blue Rock.

Early Transparent Gage.

Oullin's Golden Gage.

Mallard.

Denniston's Superb.

McLaughlin's Gage.

Green Gage.

Belgian Purple.

Golden Esperen.

Bryanston Gage.

Jefferson.

Reine Claude du Comte Atthems.

Kirke's.

Transparent Gage. 
Late Transparent Gage.

Monarch.

Golden Transparent Gage.

Reine Claude de Bavay.

I ate Orange.

Coe's Golden Drop.

Grand Duke.

\section{Cherries.}

Belle de St. Tronc.

Guigne Annonay.

Early Rivers.

Semis de Burr.

Elton.

Frogmore Bigarreau.

Grovernor Wood.

Bedford Prolific.

Black Circassian.

Reine Hortense.

White Bigarreau.

Florence.

Bigarreau Noir de Guben.

Géante d'Hedelfingen.

Monstreuse de Mezel.

Emperor Francis.

I ate Black Bigarreau.

Bigarreau Napoleon. 


\section{EXPIANATORY NOTES TO PLANS}

Plan No. 1.-This is the end elevation of a house $18 \mathrm{ft}$. wide, of any length.

From bottom course of bricks to plate, $5 \mathrm{ft}$. From ground to apex, $10 \mathrm{ft}$. Door, $7 \mathrm{ft}$. by $3 \mathrm{ft}$., with one upright bar above panel for glass.

On p. 6 reference is made to the lever as being the best ventilating gear. No section of lever is shown in plans of house, for obvious reasons. Many horticultural builders have their own patent levers, and would prefer to use them. Under these circumstances, the form of lever had better remain an open question.

Plan No. 2.--This is a section of house showing the columns, which are 2 ins. in diameter; also the cross tie-irons, $\frac{3}{4}$ in. in diameter. 2-in. $\mathbf{T}$ iron to run in centre of roof the whole length of house on each side. Columns will fit into $\mathrm{T}$ iron.

Plan No. 3.-This is a ground plan of house $50 \mathrm{ft}$. long, $18 \mathrm{ft}$. wide, showing 9-in. brickwork, door-posts, door, and position of columns.

Plan No. 4._- This is the side elevation, facing 
south, and showing position of top ventilators, and also the arrangements of posts, starting with a 2-in. post from corner posts, and then 3-in. posts alternately. Also showing front rentilators the length of every fourth post.

Pran No. 5.- This is a bird's-eye view of roof, showing position of top ventilators on each side.

Note.- The rafters of the house are $1 \frac{1}{2}$ ins. wide and $4 \frac{1}{2}$ ins. deep. The size of rebate is $\frac{1}{2}$ in. by $\frac{3}{4}$ in. 


\section{N D E X}

APHIS, 79

Apples, 73

Apricots, kinds of, 71

Arrangement of trees, 21, ․․ㄹ

Buos, 26

Birds, protection from, 16, 17

Borders, :24, 25

Bushes, 31

Cherres, kinds of, $7: ;$

Construction of houses, 1

Cost of construction, 19

Decoration, trees for, 101

Dimensions of houses, $3, \pm, 8$

EARWIGs, 80

Fintuazation of flowers, 87

Figs, kinds of, $7 \mathrm{6}$

Forcing, 41

liorms of trees, 31

Fruits, flavour of, 100

gathering of, 100

kinds of, 69,103

number of, $6:$ ?

Fumigation, 84

Furnishing, 21

Gatheriag the firuit, time for, 100

Green-fly, 79

HALF-STANDARDS, 23, 31

Hide-bound trees, 60
Houses, coustruction of, 1 cost of erection, 19 .

inexpensive, 13

lean-to, 11

span-roofed, 2

three-quarter span, 11

wire houses, 15

INSECTS, 79

Insecticides, 82, 83

KILN-DUST, 61

LEAN-To houses, 11

Longevity of pot-trees, $6 ;$

Manures, 93

Mildew, 82

Mulberry, 74

Nectarines, kinds of, 71

Number of fruits, 62

Peaches, kinds of, 69,71

Pears, kinds of, 73

Pinching, 56

Plums, kinds of, 72

Potting, :3:3

Pots, perforated, 40

Pot-trees for decorative purposes, 101

Pruning, 43

Pyramids, 23, 31

Quassia, 82

RED spider, 79

Rivers, Messrs., 2 


\section{INDEX}

SITE, :-

Soil, 33

Span-roofed houses, :-

Stocks, 2

Surface-dressing, 61

Temperature, 86

Three-quarter span, houses, 11

Thrip, 80

Trees, arrangement of, 21, ․ㅡ cost of, $63-65$

Trees, forms of, 2 (4, 31-:i:

hide-bound, 60

Vextilatros, 4

Ventilators, $1:$

rine, 7

W ATER, 18

Weevil, 81

Wire houses, 1:;

'THE ENI)

PRINTED BY WILLIAM CLOWES AND SONS, LIAITED, LONDON AND DECCLES, 


\section{BOOKS ON GARDENING}

A HANDY BOOK OF HORTICULTURE. An

Introduction to the Theory and Practice of Gardening. By F. C. Hayes, M.A., Rector of Raheny, Lecturer in Practical Horticulture in Alexandra College, Dublin. With Illustrations. Crown 8 ro. 2s. $6 d$. net.

" Not so big that it need frighten the ardent amateur, nor so much of a primer that it may be disdained by the fairly accomplished gardener, it has a good scheme. The first part, consisting of eight chapters of general principles, in simple, non-technical language, is a model of useful information in a small space; the second part deals with departments of gardening; the third, with types of flowers; and the fourth is a calendar to work by." - Daily Clronicle.

THE SOIL. An Introduction to the Scientific Study of the Growth of Crops. By A. D. Hall, M.A. (Oxon.), Director of the Rothamsted Station (Lawes Agricultural Trust). Formerly Principal of the South-Eastern Agricultural College. With 16 Illustrations. Crown 8vo. Price $3 s$. $6 d$.

"Excellent and up-to-date. . . The complete knowledge of the soil and the part it plays in the nutrition of the plants requires investigation along three lines, which may be roughly classed as-chemical, physical, or mechanical and biological. It is exactly these with which the author deals, and although it is in no sense an exhaustive treatise, a general outline has been given of all the recent investigations which have opened up so many soil problems, and thrown new light on difficulties that are experienced in practice."-Gardaners' Chronicle.

GREENHOUSE AND STOVE PLANTS. Flowering and Fine-leaved Palms, Ferns and Lycopodiums, with full details of the Propagation and Cultivation of 500 Families of Plants. By Tromas Baines. With numerous Illustrations. Medium 8vo. I2s.

\section{WORKS BY WILLIAM ROBINSON}

THE ENGLISH FLOWER GARDEN. An Illustrated Dictionary of all the Plants used, and Directions for their Culture and Arrangement. With numerous Illustrations. Medium 8vo. I5s. $\frac{1}{2}-$ Morocco, 2 Is. net. Also 2 vols., $\frac{1}{2}-$ Morocco, 24s. net.

THE WILD GARDEN. On the Naturalization and Natural Grouping of Hardy Exotic Plants, with a Chapter on the "Garden of British IVild Flowers." Illustrated by ALFRED PARSONS. Demy 8vo. Ios. 6d. net.

ALPINE FLOWERS FOR GARDENS. Rock, Wall, Marsh Plants, and Mountain Shrub. Revised Edition. With lllustrations. Medium 8vo, Ios. 6d. net.

NATURE TEACHING. Based upon the General Principles of Agriculture. For the use of Schools. By Francis WA'J's, B.Sc., F.I.C., F.C.S., Government Analytical and Agricultural Chemist, Leeward Islands, West Indies, and William G. FrEE.M.1., B.Sc., A.R.C.S., F.L.S., Superintendent of the Colonial Collections, Imperial Institute; late Scientific Assistant, Imperial Department of Agriculture for the West Indies, and formerly Demonstrator in Botany, Royal College of Science, London.

Contents:-The Seed-The Root-The Stem-The Leaf-The SoilI'lant Food and Manures-Flowers and Fruits-Weeds-Auimal Pests of Plants. Iarge Crown 8vo. $3^{s}$. $6 d$. 
A COTSWOLD VILLAGE; or, Country Life and l'ursuits in Gloucestershire. By J. ARTHUR GibBs. With Portrait and many Illustrations. Large Crown 8 vo, $6 s$.

"It is a delightful work."-Pall Mall Gazette.

"It has been a real pleasure to read it."-The Guardian.

THE NEW FOREST. Its Traditions, Inhabitants, and Customs. By Rose C. De Crespigny and Horace Hutchinsox. With a Photogravure Frontispiece and other Illustrations, and a Map. Crown 8vo. 2s. 6d. net.

"Brightly written by those who know the subject well, it is the most readable little work concerning one of England's best heritages that is known to us." -Conntry Life.

IANTO THE FISHERMAN, and other Sketches of Country Life. By Alfred W. ReEs. With Illustrations. Large Crown 8vo.

AN INDIAN GARDEN. By Mrs. Henry Cooper EgGaR. With Illustrations. Square Demy 8vo.

WILD LIFE AT THE LAND'S END. Records and Observations of the Habits and Haunts of the Fox, Badger, Otter, Seal, etc., and of their Pursuers in Cornwall. By J. C. TregartheN,

With Illustrations. Square Demy 8vo. 10s. 6d. net.

"Mr. Tregarthen not only knows what he is writing about, but he knows how to write. The result is a singularly charming volume, which will be read with delight not only by lovers of one of the most fascinating of English counties, but by all who follow the chase of the otter, the badger, and the fox." -County Gentleman.

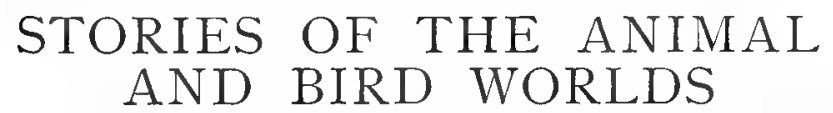

By CLARA D. PIERSON. Illustrated by F. C. GORDON. AMONG THE GARDEN PEOPLE. With Illustrations. Crown 8vo. 5s.

AMONG THE FARMYARD PEOPLE. With Illustrations. Crown 8vo. $5^{\text {s. }}$

"The stories are perfectly charming. . . one could not give a child a better present." - Queen.

AMONG THE FOREST PEOPLE. With Illustra-

tions. Crown 8vo. 5 s.

"A charming publication, suitable for young readers."-Morning Post.

AMONG THE POND PEOPLE. With Illustrations.

Crown 8 vo. 5 s.

"A book of pure delight, most charmingly illustrated."-Pall Mall Gazette.

“. . A more charming book for young children could hardly be imagined. . . . The frogs and cranes and caddis worms talk together with a delightful simplicity, and tell about themselves just those things that interest a child and make him realize the real conscious existence of the smaller creatures. . . . We canrot recommend too highly this pretty child's book." - The Literary World.

AMONG THE NIGHT PEOPLE. With Illustrations. Crown 8vo. 5 s.

"We should be sorry for the children who are not grateful to Miss Pierson for following up 'Among the Forest People' and 'Pond People' by these quaint and delightful little sketches of the manners and customs of raccoons, weasels, deer, mice, humming birds, fireflies, and other 'night people.' . . . The book deserves to become a 'nursery classic." "-The Bookseller.

\section{JOHN MURRAY, ALBEMARLE STREET, W.}





r.

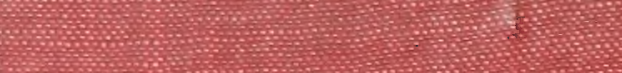

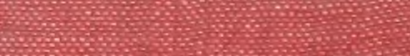
W

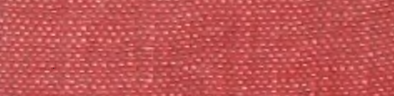

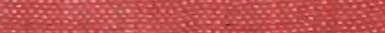
W W

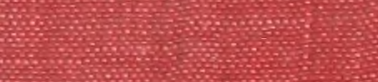
WH.

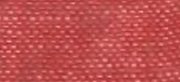

(1)

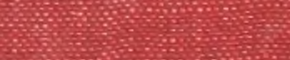

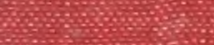

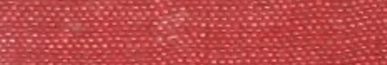

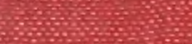

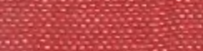

SY

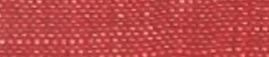

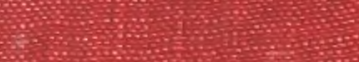

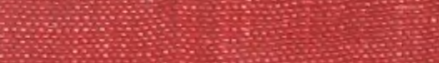

H.

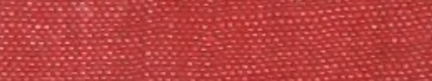

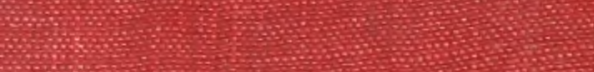

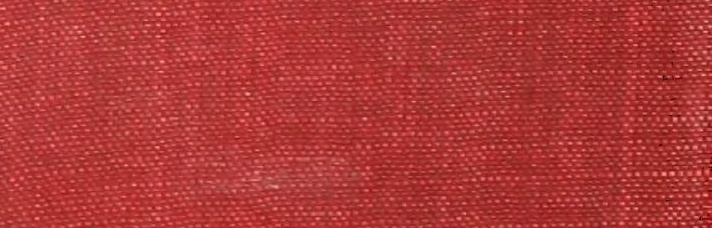

$+\bar{x} \bar{x}$ 